\title{
Gammaretroviral vector encoding a fluorescent marker to facilitate detection of reprogrammed human fibroblasts during iPSC generation.
}

Induced pluripotent stem cells (iPSCs) are becoming mainstream tools to study mechanisms of development and disease. They have a broad range of applications in understanding disease processes, in vitro testing of novel therapies, and potential utility in regenerative medicine. Although the techniques for generating iPSCs are becoming more straightforward, scientists can expend considerable resources and time to establish this technology. A major hurdle is the accurate determination of valid iPSC-like colonies that can be selected for further cloning and characterization. In this study, we describe the use of a gammaretroviral vector encoding a fluorescent marker, mRFP1, to not only monitor the efficiency of initial transduction but also to identify putative iPSC colonies through silencing of $m R F P 1$ gene as a consequence of successful reprogramming. 
1 Narasimhachar Srinivasakumar' ${ }^{1}$, Michail Zaboikin ${ }^{1}$, Andrew M. Tidball ${ }^{2}$, Asad A. Aboud $^{2}$, M.

2 Diana Neely ${ }^{2}$, Kevin C. Ess ${ }^{2}$, Aaron B. Bowman ${ }^{2}$, Friedrich G. Schuening ${ }^{1}$

3 'Division of Hematology/Oncology, Department of Internal Medicine, Saint Louis University,

4 Saint Louis, Missouri, USA

$5{ }^{2}$ Vanderbilt University Medical Center, Department of Neurology, Vanderbilt Kennedy Center for

6 Research on Human Development, Nashville, Tennessee, USA

\section{Corresponding author:}

8 Srinivas N. Kumar

9 Division of Hematology/Oncology, Department of Internal Medicine, Saint Louis University,

10 Saint Louis, Missouri, USA

$11 \quad 314-977-5312$

12 skumar15@slu.edu 
Introduction

14 Induced pluripotent stem cells (iPSCs) have many properties of embryonic stem cells and, therefore, hold great promise for their widespread utility in understanding stem cell biology and furthering regenerative medicine (Yamanaka 2012). Retroviral and Epstein-Barr virus based vectors encoding either the "Yamanaka" (Oct4, Klf4, Sox2, c-Myc or L-Myc, Lin28, and anti-p53 shRNA) (Okita et al. 2011; Takahashi et al. 2007) or "Thompson" (Oct4, Sox2, Nanog, Lin28) (Yu et al. 2009; Yu et al. 2007) reprogramming factors (RFs) can be used to generate iPSCs. Alternative methodologies to generate iPSCs using proteins, nonviral minicircle vectors, synthetic modified RNA, or small molecules have also been described ( $\underline{\text { Jia et al. 2010; Kim et al. }}$ 2009; Warren et al. 2010; Yu et al. 2011; Zhou et al. 2009). PSC reprogramming appears to be a consequence of changes in DNA methylation patterns and histone modifications resulting in chromatin remodeling (Liang \& Zhang 2013). Previously active regions responsible for the differentiated cellular phenotype are silenced while other regions are concomitantly activated to yield a gene expression pattern similar to that seen in embryonic stem cells (Maherali et al. 2007; Stadtfeld et al. 2008). The reprogramming is initiated by transient expression of RFs and follows an orderly process delineated during derivation of murine iPSCs ( Stadtfeld et al. 2008). Alkaline phosphatase activation is an early discernable event followed by silencing of fibroblast specific genes such (e.g., THY1, COL5A2, FBN2). Expression of endogenous stem cell genes including SSEA-1 appears. Finally, silencing of retroviral vector-derived gene expression is seen in conjunction with activation of endogenous OCT4 and NANOG genes. More recent investigations reveal that initial stochastic gene expression patterns, following initiation by the RFs, precede the more orderly and deterministic expression patterns identified at subsequent stages of reprogramming \{Buganim, 2012 \#5127; (Hanna et al. 2009) .

While the techniques for generating iPSCs might appear simple, accurate identification of fully reprogrammed iPSC colonies can prove difficult. The observation that successful reprogramming of cells to iPSC-like state is associated with a loss of expression of genes under control of the retroviral long terminal repeat (LTR) promoter enabled us to exploit this feature for identification of promising iPSC colonies. Here, we describe the use of a gammaretroviral vector encoding a fluorescent marker for not only ensuring adequate transduction efficiency of fibroblasts but also to identifying putative iPSC colonies based on silencing of the mRFPl marker gene.

\section{Materials and methods}

Cells. Human embryonic kidney 293T (HEK293T) cells were obtained from American Type Culture Collection (ATTC; catalog number SD-3515) and maintained in Dulbecco's modified Eagle's medium containing $2 \mathrm{mM}$ L-glutamine, $100 \mathrm{U} / \mathrm{ml}$ of penicillin, $100 \mu \mathrm{g} / \mathrm{ml}$ streptomycin and 10\% heat-inactivated fetal bovine serum (FBS) (Hyclone/ThermoFisherScientific, USA). Human lung fibroblasts were obtained from ATCC (MRC-5, catalog number CCL-171) and maintained in Eagle's minimal essential medium containing 10\% FBS. Mouse ES feeder cells (SNL-76/7-4) that express leukemia inhibitory factor (LIF) and puromycin phosphotransferase were obtained from Wellcome Trust Sanger Institute and maintained in Knockout DMEM with $7 \%$ FBS, Penicillin $(50 \mathrm{U} / \mathrm{ml})$ and Streptomycin $(50 \mu \mathrm{g} / \mathrm{ml})$. The mouse feeder cells are also available from ATCC (catalog number SNLP 76/7-4).

Plasmids. The following plasmid vectors were obtained from Addgene.org: Plasmids pMXshOCT3/4 (catalog number 17217), pMXs-hSOX2 (catalog number 17218), pMXs-hKLF4 (catalog number 17219), and pMXs-hc-MYC (catalog number 17220) were made available by the Yamanaka laboratory. Plasmids pUMVC (encodes Murine leukemia virus Gag/Pol, catalog 
number 8449), and pCMV-VSV-G (encodes VSV-G envelope, catalog number 8454) were made available by the Weinberg laboratory. Plasmid pMXs-mRFP1 encodes monomeric red fluorescent protein (Hotta et al. 2009b) (catalog number 21315) and was made available by the Ellis laboratory.

Production of vector stocks. Vector stocks were produced in HEK293T cells using $\mathrm{CaPO}_{4^{-}}$ mediated transient transfection protocol (Srinivasakumar 2002). In preparation for transfection, T-75 cell culture flasks were seeded with $7.5 \times 10^{6}$ HEK293T cells on the previous day. The plasmid DNAs $(7.5 \mu \mathrm{g}$ of pUMVC, $0.6 \mu \mathrm{g}$ of pCMV-VSV-G and $22.5 \mu \mathrm{g}$ of the gene-transfer vector encoding the RF or mRFP1) were resuspended in $1.5 \mathrm{ml}$ of $\mathrm{CaCl}_{2}$ solution $(0.25 \mathrm{M})$. The DNA was precipitated by adding drop wise $1.5 \mathrm{ml}$ of HEPES buffered saline, $\mathrm{pH} 7.05$ (50 mM HEPES, $10 \mathrm{mM} \mathrm{KCl}, 12 \mathrm{mM}$ dextrose, $280 \mathrm{mM} \mathrm{NaCl}, 1.5 \mathrm{mM} \mathrm{Na}_{2} \mathrm{HPO}_{4}$ ), while bubbling air through the DNA-CaCl 2 solution. The mix was immediately distributed drop wise onto the HEK293T cells. The following day, the medium was replaced with fresh medium, and vectorcontaining supernatant was harvested 48 hours later by centrifugation at $1,400 \mathrm{xg}$ for $15 \mathrm{~min}$ at $4^{\circ} \mathrm{C}$ and stored at $-80^{\circ} \mathrm{C}$ in aliquots. After determination of vector titers (see below), pools of required vectors were made to give the desired multiplicity of infection (MOI), and concentrated by ultracentrifugation at $100,000 \mathrm{x}$ g for 2 hours at $4^{\circ} \mathrm{C}$. The pelleted vectors were resuspended in a minimal volume of complete MRC-5 growth medium for transduction of human fibroblasts (see below).

\section{Determination of vector titers. HEK293T cells were seeded in 6-well plates $\left(2.5 \times 10^{5}\right.$} cells/well) the day prior to infection. The next day, an aliquot of the vector-containing supernatant was added to the cells in one $\mathrm{ml}$ of fresh medium containing $8 \mu \mathrm{g}$ of polybrene. After overnight incubation, polybrene was diluted by adding an additional $2 \mathrm{~mL}$ of fresh medium. The following day, the cells were rinsed several times with PBS and released by trypsin-EDTA treatment. The cells were pelleted and washed with PBS prior to isolation of genomic DNA using DNeasy kits from Qiagen (Maryland, USA) using the manufacturer's recommended protocol and included an RNAse I treatment step.

The vector and $\beta$-actin copy numbers in the isolated genomic DNA were determined using qPCR in a Bio-Rad MyiQ thermocycler. Each qPCR reaction was carried out in a $25 \mu \mathrm{L}$ final volume of iQ SYBR Green Supermix containing $60 \mathrm{ng}$ of genomic DNA and $200 \mathrm{nM}$ of each primer. We used a two-step PCR with a $95^{\circ} \mathrm{C}$ for 20 seconds denaturation step and $63.1^{\circ} \mathrm{C}$ for 45 seconds annealing and extension step. A final melt-curve analysis was done with $0.5^{\circ} \mathrm{C}$ temperature increments.

Transduction of human lung fibroblasts. MRC-5 fibroblasts were seeded in 6-well plates $(60,000$ cells/well). The cells were transduced on two consecutive days with pooled vector stocks containing all four RF vectors and the mRFP1 vector at an MOI of 5 using the "spintransduction" method. This was done by centrifuging the plates at 1,200 $\mathrm{x} g$ for 2 hours at room temperature $\left(24^{\circ} \mathrm{C}\right)$ after the addition of the vectors in $1 \mathrm{~mL}$ of MRC-5 medium containing 8 $\mu \mathrm{g} / \mathrm{mL}$ of polybrene. The plates were returned to the incubator after adding an additional $1 \mathrm{~mL}$ of medium. Forty-eight hours after the second spin-infection, the fibroblasts were split at a ratio of 1:6 and maintained for 3 more days in MRC-5 medium before seeding for reprogramming on mouse embryonic feeder cells.

Preparation of mouse ES feeder cells. SNL 76/7-4 cells were grown to about $90 \%$ confluency, washed once with PBS and incubated in SNL growth medium with $10 \mu \mathrm{g} / \mathrm{ml}$ Mitomycin C (Sigma, Saint Louis, USA, Catalog number M4287) for 2 hours at $37^{\circ} \mathrm{C}$. The cells were washed 
104 three times in excess PBS, released with Trypsin-EDTA and frozen in aliquots and stored in

105 liquid nitrogen.

106 Reprogramming of MRC-5 cells after transduction. In preparation for reprogramming, 6-well 107 plates were coated with gelatin (0.1\%, Millipore corp. USA, Catalog number ES-006-B)

108 overnight at $37^{\circ} \mathrm{C}$. The next-day Mitomycin-treated mouse ES feeder cells (SNL 76/7-4) were 109 seeded onto 6-well plates (500,000 cells/well). The following day, each well received 10,000 110 transduced MRC-5 fibroblasts in MRC-5 medium. The medium was changed the following day 111 to human ES reprogramming medium (Knockout DMEM/F12 containing 20\% Knockout serum 112 replacer (KOSR), $100 \mu \mathrm{M}$ non-essential amino acids, $100 \mu \mathrm{M}$ 2-mercaptoethanol, $1 \mathrm{mM} \mathrm{L}$ 113 glutamine, $50 \mathrm{U} / \mathrm{mL}$ penicillin, $50 \mu \mathrm{g} / \mathrm{ml}$ streptomycin, and $10 \mathrm{ng} / \mathrm{ml}$ basic fibroblast growth 114 factor (bFGF, Millipore, Massachusetts, USA). The medium was replaced every other day for 115 about 10 days and then replaced daily for additional one to 2 weeks until putative iPSC-like 116 colonies appeared and grew to a size that could be manually picked. The iPSC-like colonies were 117 marked using an object marker (BioIndustrial Products, USA, Catalog number 14361) and picked 118 using drawn out Pasteur pipets in a laminar floor hood under a stereomicroscope. Picked colonies were deposited on Mitomycin C-treated SNL feeder layer containing cells in either 24-well or 6well plates. In later experiments we determined that we could directly transfer iPSC-like clones onto feeder-free Matrigel (Beckton-Dickinson, USA) -coated wells. The cells were gradually transitioned to a feeder-free defined medium (mTeSR1, STEMCELL Technologies, Vancouver, Canada), over a 4-day period by increasing its percentage by 25\% each day (Neely et al. 2011). Individual clones were expanded and frozen down in aliquots using mFreSR (STEMCELL Technologies, Vancouver, Canada) as per the manufacturer's recommended protocol.

\section{Characterization of iPSCs.}

Alkaline phosphatase. The iPSC clones were stained for the alkaline phosphatase pluripotency marker using either fixed or live cultures. For fixed cultures we used a kit from Sigma (Saint Louis, Missouri, USA; Catalog number 85L1-1KT), while for unfixed cultures we used the Alkaline Phosphatase Live Stain (Molecular Probes/Life Technologies, Grand Island, NY, USA; Catalog number A14353) as per the manufacturers' recommended protocols.

Immunofluorescence assay for stem-cell markers. The putative iPSC clones were assessed for the expression of SSEA3, SSEA4, Tra-160, Tra-1-81 surface antigens and Oct4 and Nanog nuclear transcription factors using primary and fluorescent-labeled secondary antibodies as described previously (Neely et al. 2011).

Reverse-transcriptase-qPCR (RT-qPCR). Expression of pluripotency marker genes (NANOG and DNMT3B), and RFs (OCT4, SOX2, KLF4 and $c M Y C$ ), was determined using RT-qPCR of total mRNA isolated from individual IPSC clones using the primers listed in Table 3 . The endogenous RF mRNA $\left(\mathrm{RF}_{\mathrm{E}}\right)$ that originated from the cell was estimated using primers targeting either the 3' or 5' untranslated region. The total RF mRNA $\left(\mathrm{RF}_{\mathrm{T}}\right)$ was quantitated using primers situated in the coding exon and measured both endogenous and vector-originated mRNAs. Some of the primers used in this study were originally published by Chan and coworkers (Chan et al. $\underline{2009}$ ) and subsequently validated by us in other studies (Neely et al. 2011). The reverse transcription was done with Superscript III kit (Invitrogen/Life Technologies, Grand Island, NY, USA; Catalog number: 11752250) using random hexamers according to the recommended protocol. The following cycling parameters were used for qPCR: Incubation at $95^{\circ} \mathrm{C}$ for $10 \mathrm{~min}$, followed by 40 two-step cycles each consisting of $95^{\circ} \mathrm{C}$ for $15 \mathrm{sec}$ (denaturation) and $60^{\circ} \mathrm{C}$ for 60 sec (annealing and extension). The qPCR was accomplished using the Power SYBR Green Master Mix (Invitrogen/Life Technologies, Grand Island, NY, USA; Catalog number: 4367659) in a 7900HT PCR System (Applied Biosystems). 
151 Methylation-sensitive restriction enzyme qPCR (MSRE-qPCR). Genomic DNA (60 ng),

152 isolated using DNeasy Kits, was digested with 5 units of SmaI (methylation sensitive) or MscI

153 (methylation insensitive) or incubated in the absence of restriction enzyme (uncut) in the

154 manufacturer supplied buffer (New England Biolabs, Massachusetts, USA) in a $50 \mu 1$ reaction

155 volume at $37^{\circ} \mathrm{C}$ for $4 \mathrm{~h}$. The reaction was terminated by inactivating the enzymes at $80^{\circ} \mathrm{C}$ for 20

$156 \mathrm{~min}$. An aliquot of the digest $(5 \mu \mathrm{l})$ containing $6 \mathrm{ng}$ of genomic DNA was then used in qPCR

157 using primers (SK160 and SK161, Table 1) targeting the 5' Moloney murine leukemia virus LTR

158 and 5' untranslated region (UTR) (Fig. 8A). The PCR was carried out using SsoAdvanced SYBR

159 Green Supermix (Bio-Rad, Hercules, CA, USA, catalog no. 1725261) in a Bio-Rad CFX96

160 thermocycler. The PCR cycling parameters consisted of a two-step amplification cycle consisting

161 of a denaturation step at $98^{\circ} \mathrm{C}$ for 10 second and an annealing and extension step at $63.1^{\circ} \mathrm{C}$ for 30

162 seconds for a total of 40 cycles. A final melt-curve analysis was done as described above for

163 vector titer determination. The vector copies were normalized to $\beta$-actin copy numbers present in

164 the same samples as described earlier for vector titer determination.

165 Karyotyping. iPSC clones were karyotyped by Genetics Associates Inc., (Nashville, TN) or by 166 the Cytogenetics Department at Saint Louis University Medical Center (Saint Louis University,

167 Saint Louis, MO) using standard techniques.

168 Differentiation into ectodermal, mesodermal and endodermal elements through embryoid

169 body (EB) formation (Ohnuki et al. 2009). Six-well plates containing iPSCs in log-phase of

170 growth and showing large to medium sized colonies, were treated with Dispase $(2 \mathrm{mg} / \mathrm{mL}$ in

171 DMEM/F12, Invitrogen/Life Technologies, Grand Island, NY, USA) for 20 minutes at $37^{\circ} \mathrm{C}$. The

172 colonies were released by washing gently with the Dispase solution, and transferred to a $15 \mathrm{ml}$

173 conical tube. The colonies were allowed to settle to the bottom of the tube at unit gravity, washed

174 once by gently removing and replacing the supernatant with DMEM/F12, and then resuspended

175 in EB formation medium (DMEM with 20\% FBS or human ES reprogramming medium

176 described in Materials and Methods but without bFGF). The colonies in EB formation medium

177 were transferred to low-attachment T-25 flasks or 6-well plates (Corning, USA) and placed on an

178 orbital shaker in $37^{\circ} \mathrm{C}$ humidified incubator. After 8 days, with alternate day medium change, the

179 resultant EBs were transferred to 6-well plates coated with gelatin and allowed to attach and

180 spread out. After additional 8 days, with regular medium change every other day, the cells were

181 fixed using 4\% paraformaldehyde in phosphate buffered saline, $\mathrm{pH} 7.2$ and stained for

182 ectodermal ( $\beta$ III-tubulin), mesodermal ( $\alpha$-smooth muscle actin $(\alpha-S M A)$ or desmin) or

183 endodermal (Sox 17 or $\alpha$-fetoprotein ( $\alpha$-SMA)) marker expression (Neely et al. 2011).

184 Statistical calculations. The standard deviation of the ratio of means of target gene $(\mathrm{g}) \mathrm{mRNA}$

185 levels to control $\beta$-actin (c) mRNA levels was calculated as follows: $\mu_{\mathrm{g}} / \mu_{\mathrm{c}} \mathrm{X} \sqrt{ }\left[\left(\sigma_{\mathrm{g}} / \mu_{\mathrm{g}}\right)^{2}+\left(\sigma_{\mathrm{c}} / \mu_{\mathrm{c}}\right)^{2}\right]$

186 where $\mu=$ mean and $\sigma=$ standard deviation .

\section{Results}

188 Preparation and characterization of vector stocks. Vector stocks for each of the

189 reprogramming vectors (and the mRFP1vector) were prepared by transient transfection of

190 HEK293T cells as described in Materials and Methods. The Yamanaka reprogramming vectors,

191 however, do not express a marker gene that would enable easy determination of vector titer. Thus,

192 most reprogramming experiments for generation of iPSCs use a 'blind' approach for transduction

193 of target cells with an assumption of vector titer. We determined the titer of each vector stock

194 preparation by isolation of genomic DNA of transduced HEK293T cells followed by qPCR using

195 primers that targeted the packaging sequence in Moloney murine leukemia virus (Table 1). The

196 PCR product size was 231 bp long and the optimal annealing and extension temperature was 
determined to be $63.1^{\circ} \mathrm{C}$ in a preliminary temperature gradient PCR experiment. For amplification of a control cellular gene, we chose human $\beta$-actin primers that gave a product size of $250 \mathrm{bp}$. The same annealing-extension temperature was used for $\beta$-actin amplification. Standards for qPCR were prepared by diluting a retroviral vector plasmid DNA in genomic DNA isolated from untransduced control cells. $\beta$-actin standards were generated by serial 10 -fold dilution of genomic DNA. The results of vector titer determination are shown in Table 2.

203 Optimization of transduction of MRC-5 fibroblasts. MRC-5 fibroblasts were initially transduced with the mRFP1 encoding retroviral vector alone to determine optimal MOI and transduction parameters. We tested two different MOI (2.5 and 5.0), and transduction at unit gravity $(1 \mathrm{x} \mathrm{g})$ or spin-transduction at 1,200 x g for 2 hours at room-temperature. The efficiency of transduction was estimated by fluorescence microscopy (Fig. 1). The majority of MRC-5 fibroblasts were transduced at both MOIs. The fluorescence intensity was higher in the spininfection cultures than that observed at unit gravity, suggesting higher transduction efficiencies. This could not be categorically determined since the plate used for transduction at normal gravity (1 x g) seemed to have slightly lower light transmission characteristics than that used for transduction at 1,200 x $\mathrm{g}$ (as indicated by comparison of phase contrast and fluorescence images between the two plates, Fig.1). However, parallel transductions carried out on primary human keratinocytes clearly revealed the higher efficiencies of transduction at 1,200 $\mathrm{x} g$ and with an MOI of 5 (Fig. S1). To ensure that maximal numbers of cells were transduced, we chose an MOI of 5 with a spin-transduction protocol for reprogramming of MRC-5 fibroblasts. This also ensured that virtually all cells expressed the mRFP1 marker gene following transduction.

218 Reprogramming of MRC-5 fibroblasts with Yamanaka vectors and detection of putative volumes of the supernatants of the four reprogramming vectors and that of the mRFP1 encoding vectors to give an MOI of 5 for each vector and then pelleted the virus by ultracentrifugation. The pellet was resuspended in MRC-5 growth medium and used for transduction of the human fibroblast cells by two rounds of spin-transduction. The efficiency of transduction was determined as follows: 1) An aliquot of the transduced cells was analyzed by flow cytometry which indicated a transduction efficiency of 97\% (Fig. 2A). 2) Photomicrographs of phasecontrast and fluorescence microscopy were obtained (Fig. 2B) and the number of cells in each was counted using the cell-counter feature of NIH ImageJ software. Approximately $95 \%$ appeared to be transduced by this approach. 3) Genomic DNA was isolated from untransduced and vector-transduced MRC5 and subjected to qPCR for quantitation of vector and $\beta$-actin copy numbers. From this, the average number of vector copies per cell was estimated. The results are shown in Fig. 8B and indicate that each cell contained around 25 copies of vector. This number is consistent with the use of an MOI of 5 for each of the five vectors in the transduction.

233 Following two rounds of transduction, and a brief period of expansion, the MRC-5 fibroblasts 234 were plated on mouse ES feeder cells (SNL 76/7-4) (10,000 MRC-5 cells/well of 6-well plate), and the plates were observed on a regular basis in an inverted fluorescence microscope. The mRFP1 expressing MRC-5 cells exhibited a rapid expansion in culture as monitored by fluorescence microscopy. In the first two weeks after seeding on mouse feeder cells the colonies exhibited indistinct borders (Fig. 3). Between weeks 2 and 4, colonies with well-demarcated borders also appeared. Fluorescence microscopy revealed that the colonies with indistinct borders still expressed mRFP1, while the colonies with distinct borders were 'dark' i.e., did not express the marker gene (Fig. 4). Some colonies showed invasion by occasional mRFP1-positive fibroblast-like spindle shaped cells at their edges (Fig. 4). Phase-contrast microscopy revealed that the cells in mRFP1-negative colonies exhibited scant cytoplasm and had nuclei with 
244 prominent nucleoli that are characteristic of iPSCs (Fig. 4 and phase contrast image at 10x

245 magnification on the last row of Fig. 4).

246 We identified 24 colonies with iPSC-like morphology that were negative for mRFP1 expression.

247 This provided a calculated efficiency of iPSC generation of $0.04 \%((24 \div 60,000$ seeded cells $) \mathrm{x}$

248 100). Twenty-one of these were chosen for further cloning. Fourteen colonies survived picking

249 and could be adapted to feeder-free conditions on Matrigel. The subcloned iPSCs continued to

250 exhibit silencing of mRFP1 (Fig. 5). Six clones were subjected to a battery of tests to determine if

251 they exhibited iPSCs characteristics (Materials and Methods).

252 All clones expressed pluripotency markers alkaline phosphatase, SSEA3, SSEA4, Nanog, Oct4, 253 and Tra-1-60 (Fig. 6A and Fig. S2 through Fig. S6).

254 Retroviral expression of RFs is shut off following successful reprogramming. To determine the relative levels of $\mathrm{RF}_{\mathrm{E}}$ (endogenous) and $\mathrm{RF}_{\mathrm{T}}$ (endogenous and vector-derived) mRNA expression, total RNA from iPSCs and control cells, were reverse transcribed and amplified by qPCR. The mRNA levels were normalized to $\beta$-actin levels. The normalized expression patterns are shown in Fig. S7. Untransduced control MRC-5 fibroblasts expressed low levels of OCT4 and SOX2 but readily detectable levels of KLF4 and $c M Y C$. Transduced MRC-5 cells (MRC-5 $5 \mathrm{~V}$ ), in contrast, exhibited high levels of $\mathrm{RF}_{\mathrm{T}}$ in comparison to $\mathrm{RF}_{\mathrm{E}} \mathrm{mRNA}$ levels. All four RFs were raised in putative iPSCs. Counter intuitively, $\mathrm{RF}_{\mathrm{E}} \mathrm{S}$ sometimes exceeded the $\mathrm{RF}_{\mathrm{T}} \mathrm{S}$ for some RFs. To therefore control for possible differing efficiencies of amplification or reversetranscription of $R F_{T} V s F_{E}$ mRNAs, we determined $R F_{T}$ to $R F_{E}$ ratio for all samples. We then normalized these ratios for each RF to that of hES cells in which the entire contribution to the $\mathrm{RF}_{\mathrm{T}} \mathrm{mRNA}$ must originate only from endogenous source. These normalized data are shown in Fig. 7A and indicate that the putative iPSC clones exhibited an average $R_{\mathrm{T}} / \mathrm{RF}_{\mathrm{E}}$ ratio of the four RFs comparable to that in hES cells (with less than 2-fold difference). In contrast, vectortransduced MRC-5 cells, prior to reprogramming, exhibited 21- to 9,017-fold higher $\mathrm{RF}_{\mathrm{T}} / \mathrm{RF}_{\mathrm{E}}$ ratios than hES or iPSCs. The vector-derived RF expression was then significantly decreased as the endogenous cellular transcription of the corresponding factors was increased. We also determined the expression of other genes characteristic of iPSCs (NANOG, DNMT3B). These were expressed at high levels in hES and the putative iPSC clones but not in untransduced MRC5 or vector-transduced MRC-5 prior to reprogramming (MRV-5 5V) (Fig. 7B). These results indicate that the fibroblasts were fully reprogrammed.

\section{Methylation status of 5' LTR of Moloney vector in transduced MRC5 cells and derived iPSC clones correlates with gene expression studies. Silencing of expression from Moloney} LTR promoter has been associated with methylation at $\mathrm{CpG}$ islands. To determine the methylation status of the viral LTR promoter, we designed an MSRE-qPCR assay that spans SmaI (methylation sensitive) and MscI (methylation insensitive) restriction sites in the 5' LTR (Fig. 8A). The sense primer was located in the U3 region of LTR while the antisense primer was located in the 5' UTR downstream of the primer binding site (PBS). This ensured that only the 5' LTR was amplified in the qPCR assay. Genomic DNA from each of iPSC clones was isolated and then digested with SmaI or MscI or mock-digested in the appropriate buffer. An aliquot of the digest was subjected to qPCR as described in Materials and Methods. For generating methylation controls, HindIII-linearized vector plasmid ( $4 \mu \mathrm{g})$ was methylated in vitro using $\mathrm{CpG}$ methyltransferase (M.Sss1, 4 units/ $\mu$ g of DNA, New England Biolabs, Massachusetts, USA) in the supplied buffer containing $\mathrm{S}$-adenosylmethionine for $2 \mathrm{~h}$ at $37^{\circ} \mathrm{C}$. The methylation reaction was terminated by heat inactivation at $65^{\circ} \mathrm{C}$ for 20 minutes. Genomic DNA from untransduced MRC5 cells was spiked with an aliquot of unmethylated or methylated vector plasmid and used as positive and negative controls for digestion and qPCR with SmaI or MscI. Genomic DNA 
from MRC5 fibroblasts transduced with all four reprogramming vectors as well as mRFP1 encoding vector was also digested with SmaI or MscI or undigested and then subjected to qPCR as for the iPSC clones. Each of the samples was also tested by qPCR for human $\beta$-actin as described in Materials and Methods.

The results are shown in Fig. 8B and indicate that there were similar numbers of vector copies per cell for the parent transduced MRC-5 cells and the derived iPSC clones (22 to 25 copies/cell). In 5 of the 6 clones the number of vector copies per cell was identical between uncut and SmaI digested genomic DNA samples. The complete resistance to digestion by SmaI in these clones was consistent with methylation at the SmaI site. In clone 17, the genomic DNA was only partially resistant to SmaI. In contrast, in vector-transduced parent MRC-5 fibroblasts, the SmaI site was exquisitely sensitive to digestion, indicating that prior to reprogramming the site was not methylated. The in vitro methylated (MPC) and unmethylated vector plasmid (UPC) showed resistance and susceptibility to SmaI, respectively, as anticipated. In all cases, PCR amplification was significantly thwarted by predigestion with the methylation insensitive MscI in the same buffer as SmaI, indicating that the genomic DNA did not contain inhibitors to restriction enzyme digestion. These results corroborate the RT-qPCR results described above showing complete abrogation of vector derived gene expression in the tested iPSC clones. The results also explain the silencing of mRFP1 expression during reprogramming.

Further characterization of the clones (Fig. S2-Fig. S6) revealed that with the exception of clone \#16 (that showed trisomy of chromosome number 12, Fig.S4B), all other clones exhibited a normal karyotype (Fig. 6B and Fig. S2- Fig. S5). EBs derived from these clones (Fig. 9) generated cells that expressed markers of ectoderm, endoderm, and mesoderm (Fig. 6C \& Fig. S2-Fig. S6 C) supporting their pluripotency.

\section{Discussion}

During reprogramming of somatic cells to iPSCs, the gene expression profile mimics that seen in embryonic stem cells and deviates from somatic cells, such as fibroblasts, from which the iPSCs originated. The shift in expression patterns occurs in stages (Stadtfeld et al. 2008) as outlined in the Introduction. One model (Liang \& Zhang 2013) posits that there are several barriers to overcome during the reprogramming of fibroblasts to iPSCs. The first barrier is during transition from mesenchymal to epithelial (MET) phenotype, the second barrier is for transition from epithelial to nascent iPSCs during which continued expression of RF is no longer required and can pose a barrier to the final transition to bona fide iPSCs. According to this model then, the down-regulation of expression from retroviral vectors is imperative to successful reprogramming to iPSCs. Cells that continue to express retrovirally derived RFs would be trapped in a partially reprogrammed state (Jaenisch \& Young 2008; Liang \& Zhang 2013; Okita et al. 2007). Hotta and coworkers classify partially reprogrammed and fully reprogrammed fibroblasts as Class I and Class II based on retention or extinction of retroviral expression, respectively (Hotta \& Ellis 2008). The Yamanaka group also correctly predicted that continued expression of RFs from the retroviral vectors would be antithetical to subsequent pluripotent differentiation of the iPSCs into other cell types (Takahashi \& Yamanaka 2006). Papapetrou and coworkers used lentivirus vectors encoding distinct fluorescent markers linked to each of the four RFs. They found that all four vectors were silenced in successfully reprogrammed iPSCs (Papapetrou et al. 2009).

Multiple studies have uncovered possible mechanisms for gene silencing of retroviruses in embryonic cells (Cherry et al. 2000; Minoguchi \& Iba 2008) (reviewed in (Hotta \& Ellis 2008)). Various silencers have been identified in the viral LTR. These include CpG islands in the promoter region (Hilberg et al. 1987), the proline t-RNA primer binging site (PBS) that is a target 
337 of Trim28 (Wolf \& Goff 2007), a negative control region containing binding site for the 338 transcription factor YY-1, and an ELP/Nr5a1 binding site (Flanagan et al. 1989) (Fig. 8A). These 339 sites allow the targeting of enzymes or proteins to the proviral LTR that mediate epigenetic 340 modifications such as methylation of histones (H3K9 or H3K27) or DNA (i.e., methylation of 341 cytosine in $\mathrm{CpG}$ islands) that ultimately result in silencing of the promoter (Pannell \& Ellis 342 2001). The finding of de novo upregulation of cellular methyltransferase (DNMT3B) expression 343 in bona fide iPSCs could be the mechanistic link to this hypothesis (Stadtfeld et al. 2008).

344 The initial Yamanaka vectors were based on the pMXs backbone described by Kitamura and 345 coworkers ((Kitamura et al. 2003), as are the vectors used in this study. These vectors are 346 susceptible to silencing during reprogramming. In contrast, other gamma-retroviral vectors that

381 Other investigators have also engineered retroviral vectors to detect and select for successfully

382 reprogrammed cells into iPSCs. Hotta and coworkers described the EOS lentiviral vector 
383

384

385

386

387

388

389

390

391

392

393

394

395

396

397

398

399

400

401

402

403

404

405

406

407

408

409

410

411

412

413

414

415

416

417

418

419

420

421

422

423

424

425

426

427

selection system for derivation of human iPSCs (Hotta et al. 2009a). This vector encodes enhanced green fluorescent proteins and puromycin resistance gene under control of a hybrid promoter consisting of the mouse early transposon in combination with enhancers derived from OCT4 and SOX2 promoters. The puromycin selection is linked to enhanced green fluorescent protein (EGFP) expression by means of an internal ribosomal entry site. Successful reprogramming results in enhanced expression of EGFP and allows the selection of these cells using puromycin. Alternative methods of selection of reprogramming include the use of selection markers under the FBX15 (Takahashi \& Yamanaka 2006) and NANOG (Okita et al. 2007) promoters. Selection of Fbx15 expression in mouse cells resulted in iPSCs that were not fully competent to form chimeras. In contrast, selection for $N A N O G$ promoter activation resulted in mouse iPSCs that shared features with mouse ES cells. The latter experiment required the use of BACs containing the $N A N O G$ promoter driving a selection marker. The above-described approaches use positive selection strategies. In contradistinction, our approach does not call for the use of a particular promoter to positively select for reprogrammed cells, which has a potential to introduce biases during the selection process. Warlich and coworkers (Warlich et al. 2011) employed a combined approach to identify reprogrammed cells. They used lentiviral vectors encoding codon-optimized RFs and dTomato fluorescent protein under control of spleen focus forming virus promoter to reprogram mouse cells that harbored an endogenous OCT4-green fluorescent protein reporter cassette. These investigators also found that successful reprogramming correlated with silencing of exogenous RF expression with simultaneous upregulation and expression of green fluorescent protein under control of the OCT4 promoter.

The Yamanaka group previously used gammaretroviral vectors encoding fluorescent marker to demonstrate that such vectors are indeed silenced during the reprogramming step (Nakagawa et al. 2008). Studies from the Hochedlinger group (Stadtfeld et al. 2008) defined the key stages that occur during reprogramming of fibroblasts into iPSCs. Chan and coworkers (Chan et al. 2009) using live-cell imaging to identify successfully reprogrammed cells based on proviral silencing and expression of TRA-1-60, DNMT3B and REX1. Our study then builds on these earlier findings in the following ways: 1) careful determination of vector titers using qPCR; 2) use of sufficiently high MOI and spin-transduction to ensure efficient marking of virtually all target cells with mRFP1; and 3) initial screening of putative iPSC clones primarily based on silencing of mRFP1 expression and colony morphology. These modifications lead to the successful and unambiguous derivation of human iPSCs from fibroblasts.

A possible disadvantage of our method is that high efficiencies of transduction with retroviral vectors are required to ensure that nearly all of the primary cells express the marker gene. For example, we were unable to use this approach for primary human keratinocytes due to the lower efficiencies of transduction (Fig. S1). If transduction efficiency is less than optimal, an additional step of sorting the transduced primary cells will be required for identification of successfully reprogrammed IPSC colonies based on gammaretroviral silencing.

In summary, we describe a method of marking primary fibroblasts during retroviral vectormediated programming to facilitate detection and differentiation of reprogrammed from nonreprogrammed colonies. This methodology would be of value for investigators who are in the process of establishing iPSC technology in their laboratories as well as to monitor the effects of different reprogramming conditions, addition of growth factors, media changes, etc. We finally suggest that this technique may also prove useful for iPSC derivation using alternative approaches such as Sendai virus or transfection with episomal plasmids. 
Buta C, David R, Dressel R, Emgard M, Fuchs C, Gross U, Healy L, Hescheler J, Kolar R, Martin U, Mikkers H, Muller FJ, Schneider RK, Seiler AE, Spielmann H, and Weitzer G. 2013. Reconsidering pluripotency tests: do we still need teratoma assays? Stem Cell Res 11:552-562.

Chan EM, Ratanasirintrawoot S, Park IH, Manos PD, Loh YH, Huo H, Miller JD, Hartung O, Rho J, Ince TA, Daley GQ, and Schlaeger TM. 2009. Live cell imaging distinguishes bona fide human iPS cells from partially reprogrammed cells. Nat Biotechnol 27:1033-1037.

Cherry SR, Biniszkiewicz D, van Parijs L, Baltimore D, and Jaenisch R. 2000. Retroviral expression in embryonic stem cells and hematopoietic stem cells. Mol Cell Biol 20:74197426.

Flanagan JR, Krieg AM, Max EE, and Khan AS. 1989. Negative control region at the 5' end of murine leukemia virus long terminal repeats. Mol Cell Biol 9:739-746.

Hanna J, Saha K, Pando B, van Zon J, Lengner CJ, Creyghton MP, van Oudenaarden A, and Jaenisch R. 2009. Direct cell reprogramming is a stochastic process amenable to acceleration. Nature 462:595-601.

Hilberg F, Stocking C, Ostertag W, and Grez M. 1987. Functional analysis of a retroviral hostrange mutant: altered long terminal repeat sequences allow expression in embryonal carcinoma cells. Proc Natl Acad Sci U S A 84:5232-5236.

Hotta A, Cheung AYL, Farra N, Garcha K, Chang WY, Pasceri P, Stanford WL, and Ellis J. 2009a. EOS lentiviral vector selection system for human induced pluripotent stem cells. Nature protocols 4:1828-1844.

Hotta A, and Ellis J. 2008. Retroviral vector silencing during iPS cell induction: an epigenetic beacon that signals distinct pluripotent states. Journal of Cellular Biochemistry 105:940948.

Hotta A, Hotta A, Cheung AYL, Cheung AYL, Farra N, Farra N, Vijayaragavan K, Vijayaragavan K, S Eacute Guin CA, S Eacute Guin CA, Draper JS, Draper JS, Pasceri P, Pasceri P, Maksakova IA, Maksakova IA, Mager DL, Mager DL, Rossant J, Rossant J, Bhatia M, Bhatia M, Ellis J, and Ellis J. 2009b. Isolation of human iPS cells using EOS lentiviral vectors to select for pluripotency. Nature methods 6:370.

Jaenisch R, and Young R. 2008. Stem cells, the molecular circuitry of pluripotency and nuclear reprogramming. Cell 132:567-582.

Jia F, Wilson KD, Sun N, Gupta DM, Huang M, Li Z, Panetta NJ, Chen ZY, Robbins RC, Kay MA, Longaker MT, and Wu JC. 2010. A nonviral minicircle vector for deriving human iPS cells. Nature methods 7:197-199.

Kim D, Kim CH, Moon JI, Chung YG, Chang MY, Han BS, Ko S, Yang E, Cha KY, Lanza R, and Kim KS. 2009. Generation of human induced pluripotent stem cells by direct delivery of reprogramming proteins. Cell Stem Cell 4:472-476.

Kitamura T, Koshino Y, Shibata F, Oki T, Nakajima H, Nosaka T, and Kumagai H. 2003. Retrovirus-mediated gene transfer and expression cloning: powerful tools in functional genomics. Experimental hematology 31:1007-1014.

Liang G, and Zhang Y. 2013. Embryonic stem cell and induced pluripotent stem cell: an epigenetic perspective. Cell Res 23:49-69.

Maherali N, Sridharan R, Xie W, Utikal J, Eminli S, Arnold K, Stadtfeld M, Yachechko R, Tchieu J, Jaenisch R, Plath K, and Hochedlinger K. 2007. Directly reprogrammed fibroblasts show global epigenetic remodeling and widespread tissue contribution. Cell Stem Cell 1:55-70.

Minoguchi S, and Iba H. 2008. Instability of retroviral DNA methylation in embryonic stem cells. Stem Cells 26:1166-1173. 
Nakagawa M, Koyanagi M, Tanabe K, Takahashi K, Ichisaka T, Aoi T, Okita K, Mochiduki Y, Takizawa N, and Yamanaka S. 2008. Generation of induced pluripotent stem cells without Myc from mouse and human fibroblasts. Nature biotechnology 26:101-106.

Neely MD, Tidball AM, Aboud AA, Ess KC, and Bowman AB. 2011. Induced Pluripotent Stem Cells (iPSCs): An Emerging Model System for the Study of Human Neurotoxicology. Totowa, NJ: Humana Press, 56: 27-61.

Ohnuki M, Takahashi K, and Yamanaka S. 2009. Generation and characterization of human induced pluripotent stem cells. Current protocols in stem cell biology Chapter 4:Unit 4A.2.

Okita K, Ichisaka T, and Yamanaka S. 2007. Generation of germline-competent induced pluripotent stem cells. Nature 448:313-317.

Okita K, Matsumura Y, Sato Y, Okada A, Morizane A, Okamoto S, Hong H, Nakagawa M, Tanabe K, Tezuka K-I, Shibata T, Kunisada T, Takahashi M, Takahashi J, Saji H, and Yamanaka S. 2011. A more efficient method to generate integration-free human iPS cells. Nature methods 8:409-412.

Pannell D, and Ellis J. 2001. Silencing of gene expression: implications for design of retrovirus vectors. Reviews in medical virology 11:205-217.

Papapetrou EP, Tomishima MJ, Chambers SM, Mica Y, Reed E, Menon J, Tabar V, Mo Q, Studer L, and Sadelain M. 2009. Stoichiometric and temporal requirements of Oct4, Sox2, Klf4, and c-Myc expression for efficient human iPSC induction and differentiation. Proceedings of the National Academy of Sciences 106:12759-12764.

Srinivasakumar N. 2002. Packaging Cell System for Lentivirus Vectors: Preparation and Use: Humana Press Inc., Totowa, NJ.69: 275-302.

Stadtfeld M, Maherali N, Breault DT, and Hochedlinger K. 2008. Defining molecular cornerstones during fibroblast to iPS cell reprogramming in mouse. Cell Stem Cell 2:230240.

Takahashi K, Tanabe K, Ohnuki M, Narita M, Ichisaka T, Tomoda K, and Yamanaka S. 2007. Induction of pluripotent stem cells from adult human fibroblasts by defined factors. Cell 131:861-872.

Takahashi K, and Yamanaka S. 2006. Induction of pluripotent stem cells from mouse embryonic and adult fibroblast cultures by defined factors. Cell 126:663-676.

Warlich E, Kuehle J, Cantz T, Brugman MH, Maetzig T, Galla M, Filipczyk AA, Halle S, Klump H, Scholer HR, Baum C, Schroeder T, and Schambach A. 2011. Lentiviral vector design and imaging approaches to visualize the early stages of cellular reprogramming. Mol Ther 19:782-789.

Warren L, Manos PD, Ahfeldt T, Loh YH, Li H, Lau F, Ebina W, Mandal PK, Smith ZD, Meissner A, Daley GQ, Brack AS, Collins JJ, Cowan C, Schlaeger TM, and Rossi DJ. 2010. Highly efficient reprogramming to pluripotency and directed differentiation of human cells with synthetic modified mRNA. Cell Stem Cell 7:618-630.

Wikipedia. Propagation of uncertainty. Available at http://en.wikipedia.org/wiki/Propagation of uncertainty (accessed 5 November 2013).

Wolf D, and Goff SP. 2007. TRIM28 mediates primer binding site-targeted silencing of murine leukemia virus in embryonic cells. Cell 131:46-57.

Yamanaka S. 2012. Induced Pluripotent Stem Cells: Past, Present, and Future. Stem Cell 10:678684.

Yu J, Chau KF, Vodyanik MA, Jiang J, and Jiang Y. 2011. Efficient Feeder-Free Episomal Reprogramming with Small Molecules. PLOS one 6:e17557. 
524 Yu J, Hu K, Smuga-Otto K, Tian S, Stewart R, Slukvin II, and Thomson JA. 2009. Human Induced Pluripotent Stem Cells Free of Vector and Transgene Sequences. Science (New York, NY) 324:797-801.

527 Yu J, Vodyanik MA, Smuga-Otto K, Antosiewicz-Bourget J, Frane JL, Tian S, Nie J, Jonsdottir 528 GA, Ruotti V, Stewart R, Slukvin II, and Thomson JA. 2007. Induced pluripotent stem 529 cell lines derived from human somatic cells. Science (New York, NY) 318:1917-1920.

Zhou H, Wu S, Joo JY, Zhu S, Han DW, Lin T, Trauger S, Bien G, Yao S, Zhu Y, Siuzdak G, Scholer HR, Duan L, and Ding S. 2009. Generation of Induced Pluripotent Stem Cells Using Recombinant Proteins. Stem Cell 4:1-4. 


\section{Figure 1}

Spin-transduction of human fibroblast with gammaretroviral vector is more efficient than transduction at unit gravity.

Human MRC-5 fibroblasts were transduced with pMXs-mRFP1 vector at unit gravity $(1 \times \mathrm{g})$ or by spin-transduction (1,200 $\times \mathrm{g}$ for $2 \mathrm{~h}$ at room temperature). Two different MOls were used (2.5 and 5.0). The cells were visualized by phase contrast and fluorescence microscopy.

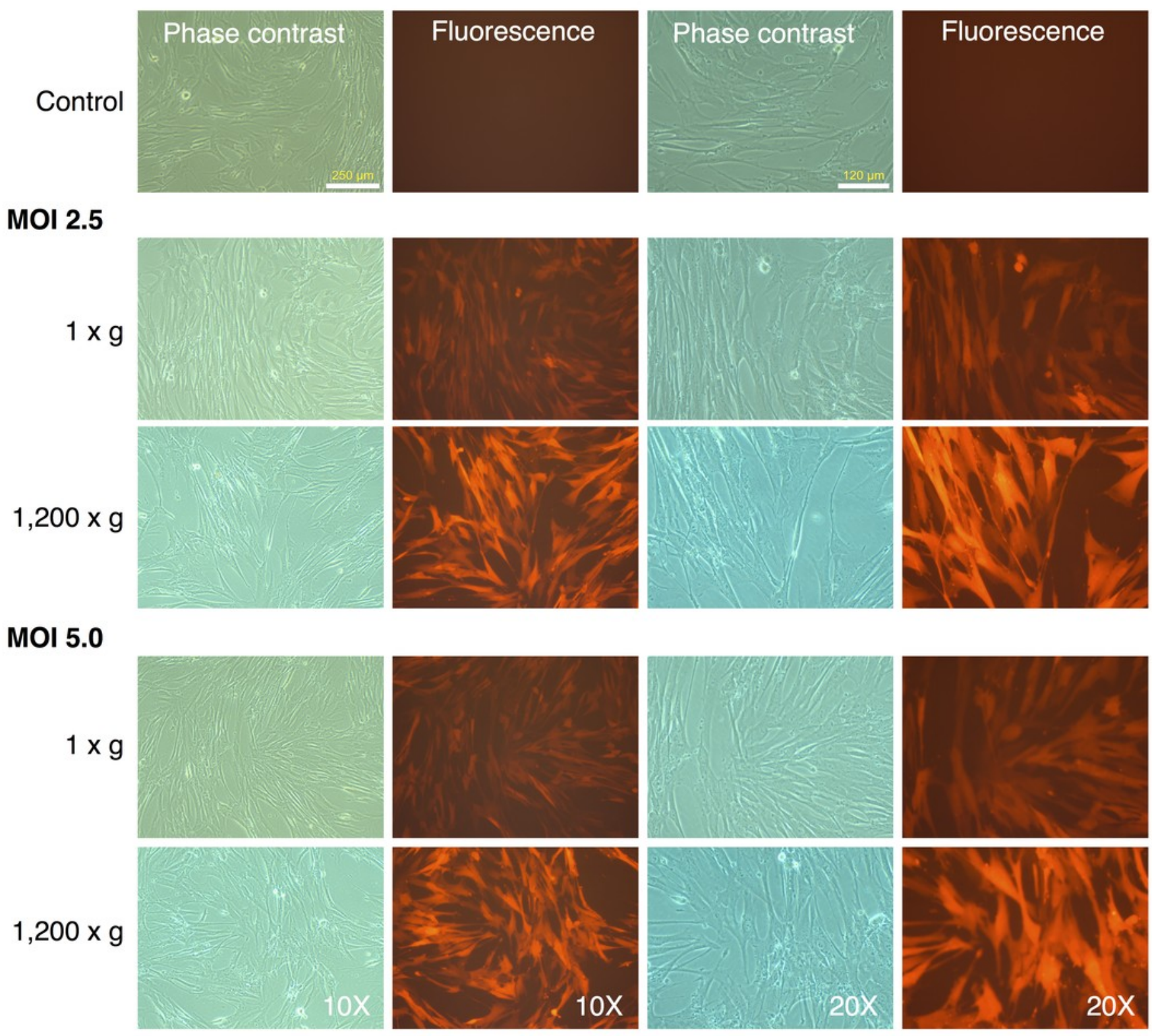




\section{Figure 2}

Efficiency of transduction of MRC- 5 fibroblasts by RF vector cocktail.

A) Untransduced and transduced MRC-5 fibroblasts (MRC-5 5V) were analyzed by flow cytometry and the percentage of transduced fibroblasts was determined after gating the untransduced cells to determine the 'negative' fraction. B) Fluorescence and phase contrast images of untransduced and transduced MRC- 5 cells. The percentage of transduced cells was determined using the cell-counter feature in NIH ImageJ software. 
A
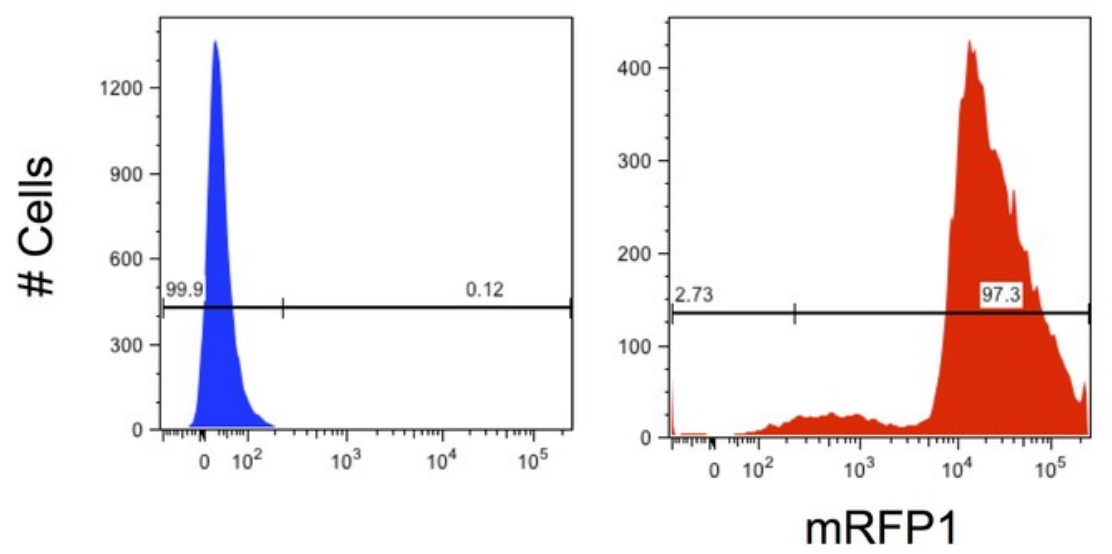
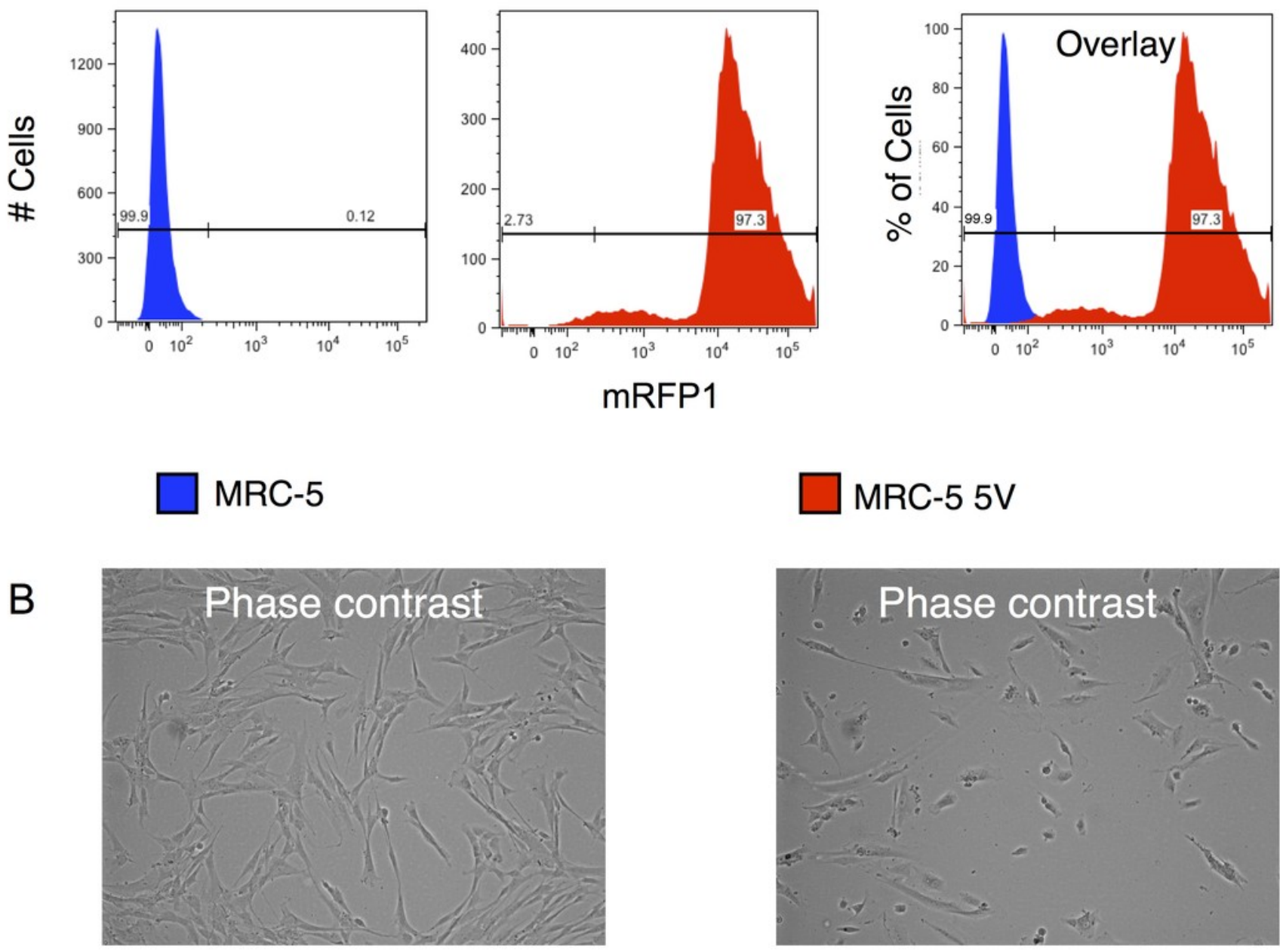

Fluorescence
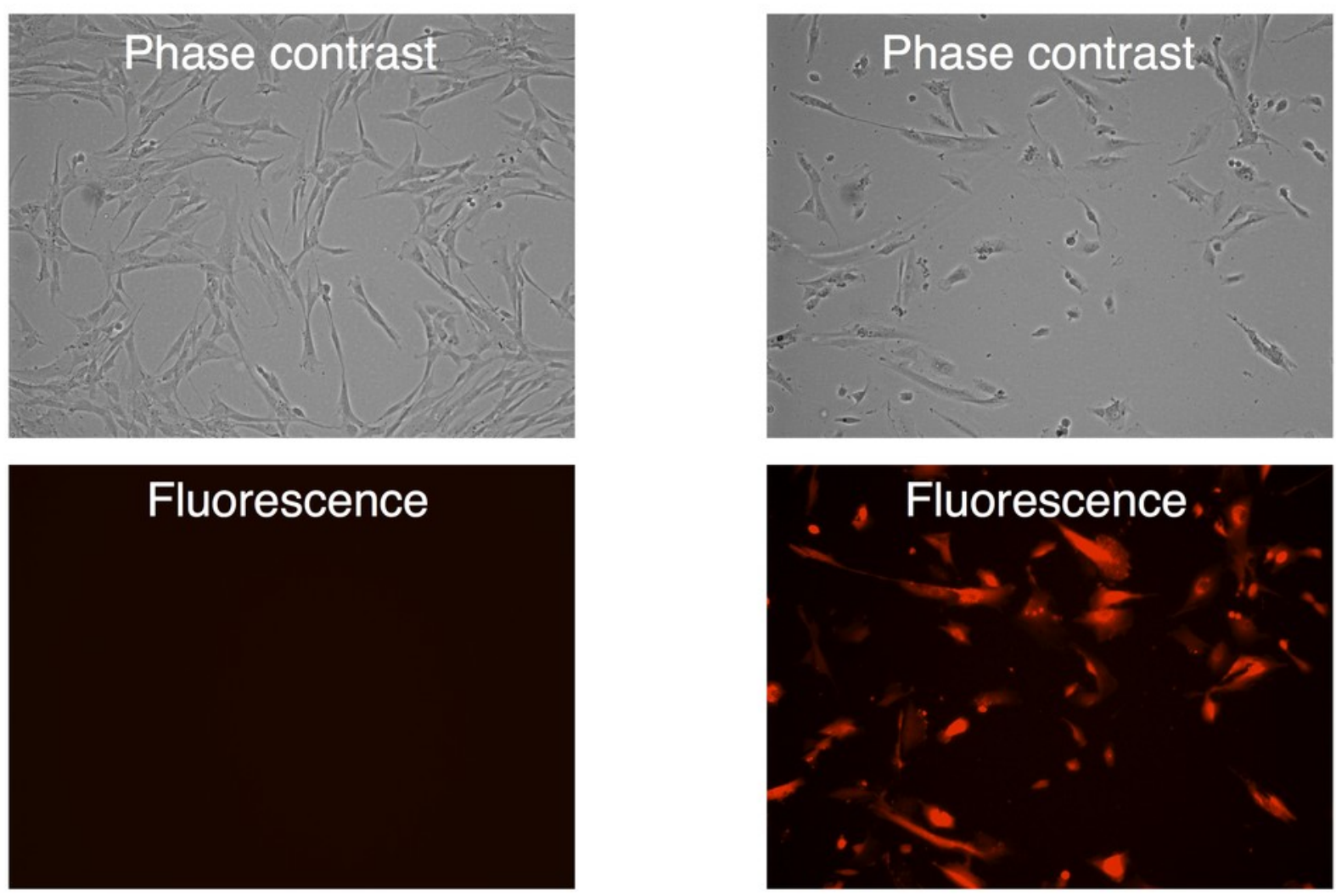


\section{Figure 3}

mRFP1-positive colonies and cell aggregates seen during reprogramming of human fibroblasts on mouse feeder cells.

Human MRC-5 fibroblasts transduced with four reprogramming Yamanaka retroviral vectors and pMXs-mRFP1 vector were seeded onto Mitomycin-C treated mouse feeder cells and cultured in human ES reprogramming medium containing bFGF. The resultant colonies and cell aggregates were visualized by phase contrast and fluorescence microscopy.
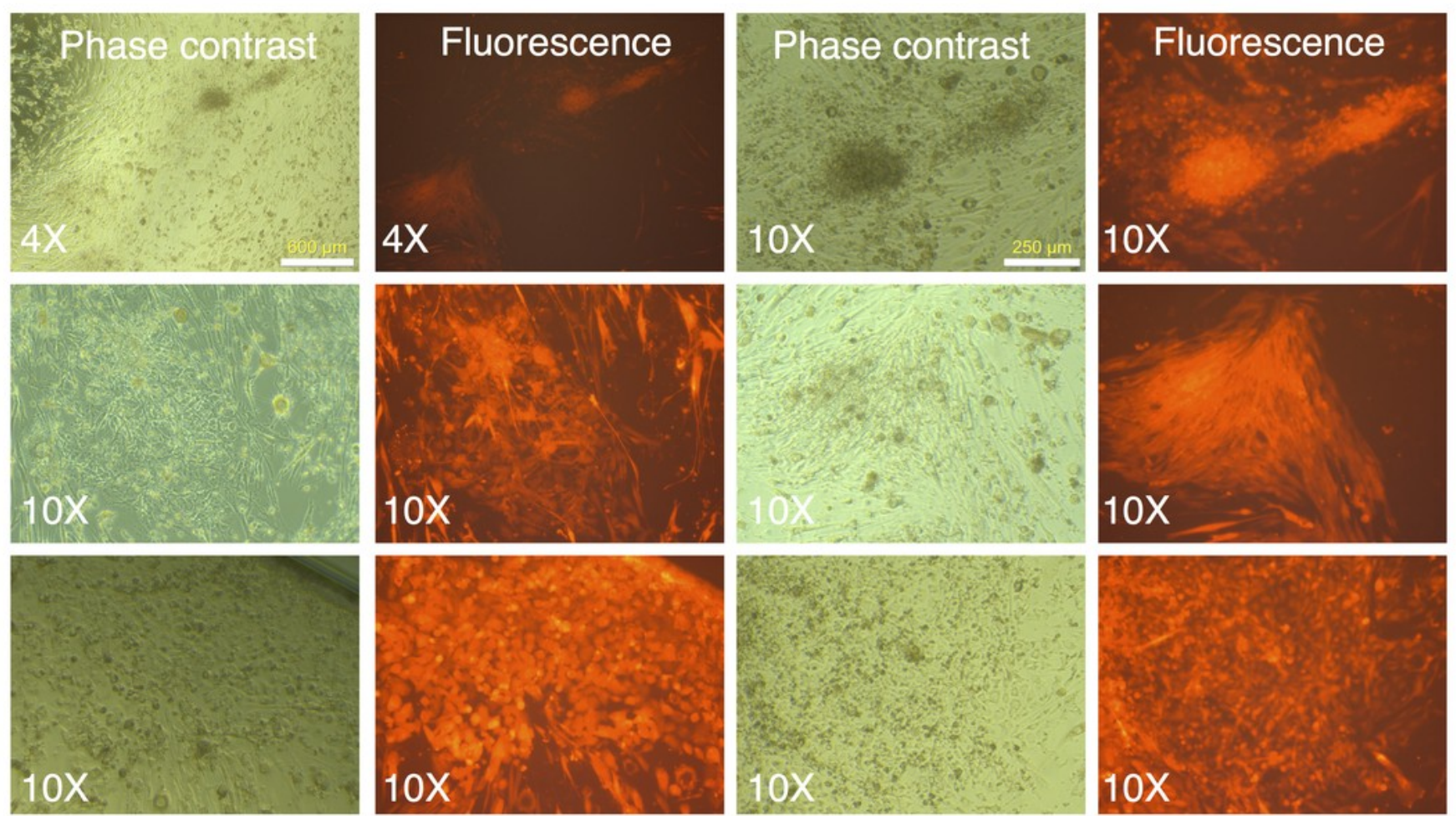


\section{Figure 4}

mRFP-1 negative putative IPSC colonies on mouse feeder cells

Human MRC-5 fibroblasts transduced with four reprogramming Yamanaka retroviral vectors and pMXs-mRFP1 vector were seeded onto Mitomycin-C treated mouse feeder cells and cultured in human ES reprogramming medium containing bFGF. The resultant colonies were visualized by phase contrast or fluorescence microscopy. The bluish-black rings and stains seen at $4 x$ magnification are the result of using an object marker to delineate putative IPSC colonies. $\left({ }^{*}\right)$ denotes a slight upward shift in field for the fluorescence image with respective to corresponding phase contrast image at 10x magnification in the top row. The images with $\left({ }^{* *}\right)$ do not have corresponding $4 x$ or $10 x$ images and are therefore to be considered in pairs of phase contrast and fluorescence images. 

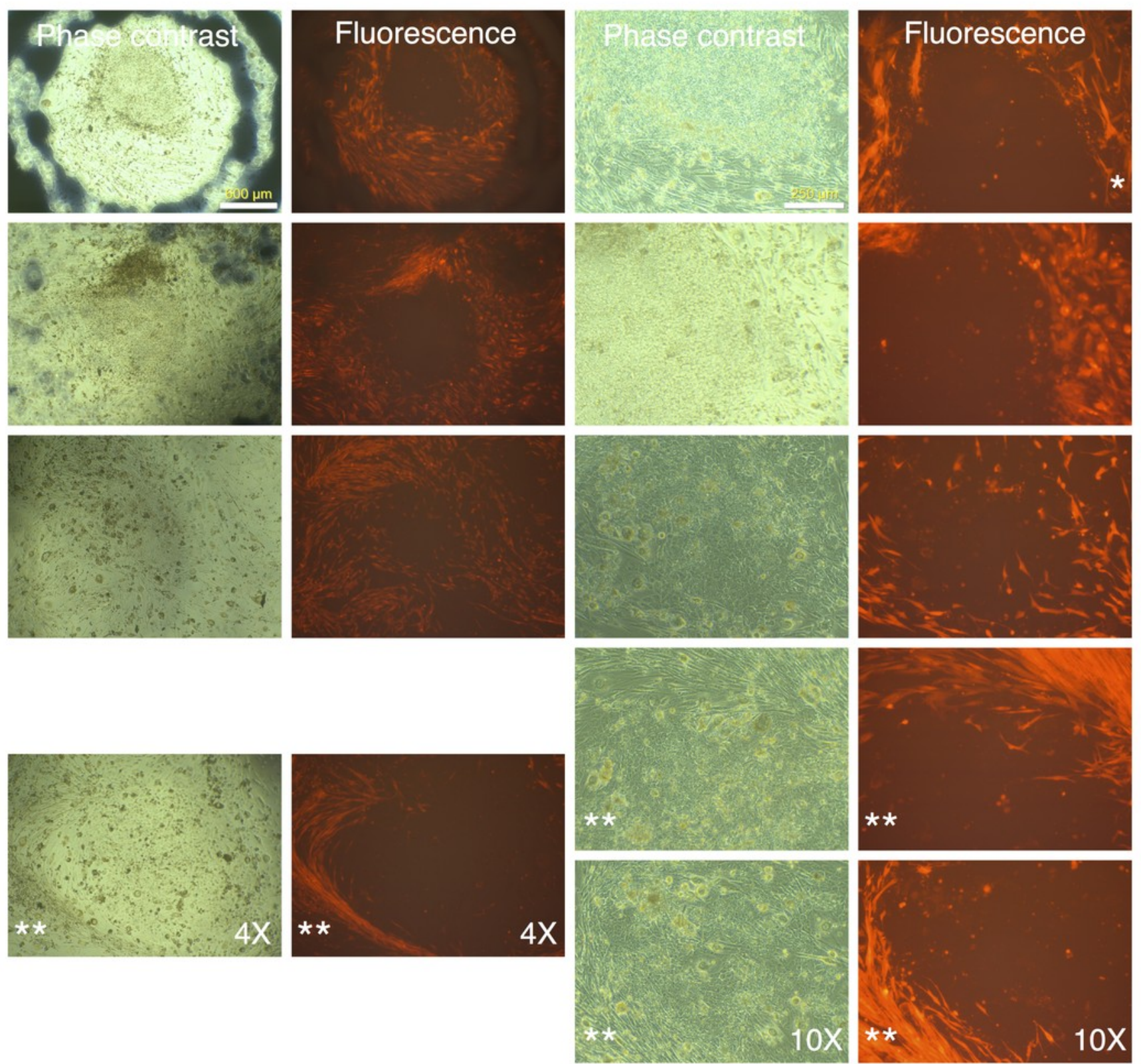


\section{Figure 5}

Cloned IPSC-like colonies retain mRFP1-negative phenotype.

mRFP1-negative colonies were picked on to fresh 6-well plates containing mouse feeder cells and visualized by phase contrast and fluorescent microscopy.
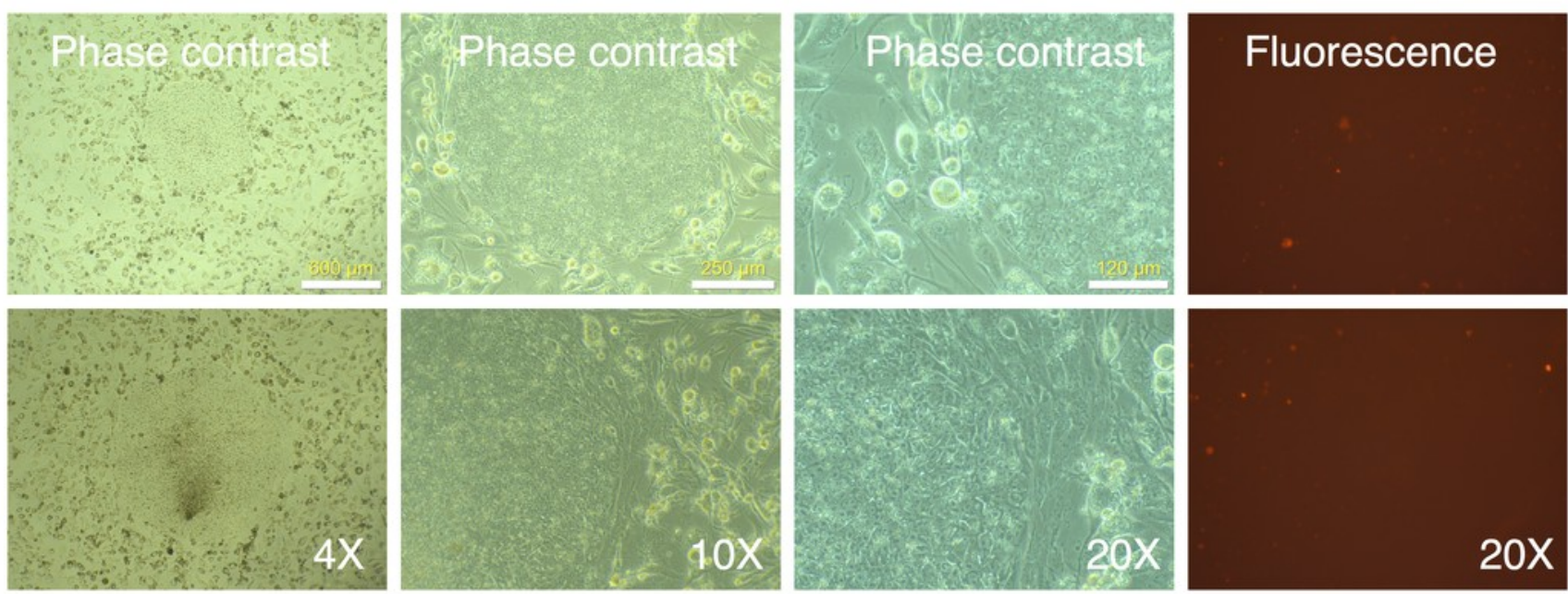


\section{Figure 6}

Characterization of putative iPSC-5 clone.

A) Parallel wells of the iPSC clone (iPSC-5) were fixed with paraformaldehyde and stained with SSEA4, Nanog, Tra-1-60 or SSEA3 and Oct4 and visualized under fluorescence microscopy. The alkaline phosphatase stained colonies were visualized under bright field microscopy. B) Karyotype of IPSC clone. C) Embryoid bodies were allowed to attach and spread out on gelatin-coated wells, fixed and stained for endodermal (Desmin), mesodermal ( $\alpha$-smooth muscle $\alpha$ ctin $(\alpha$-SMA)), or ectodermal ( $\beta$ III-tubulin) markers.

A
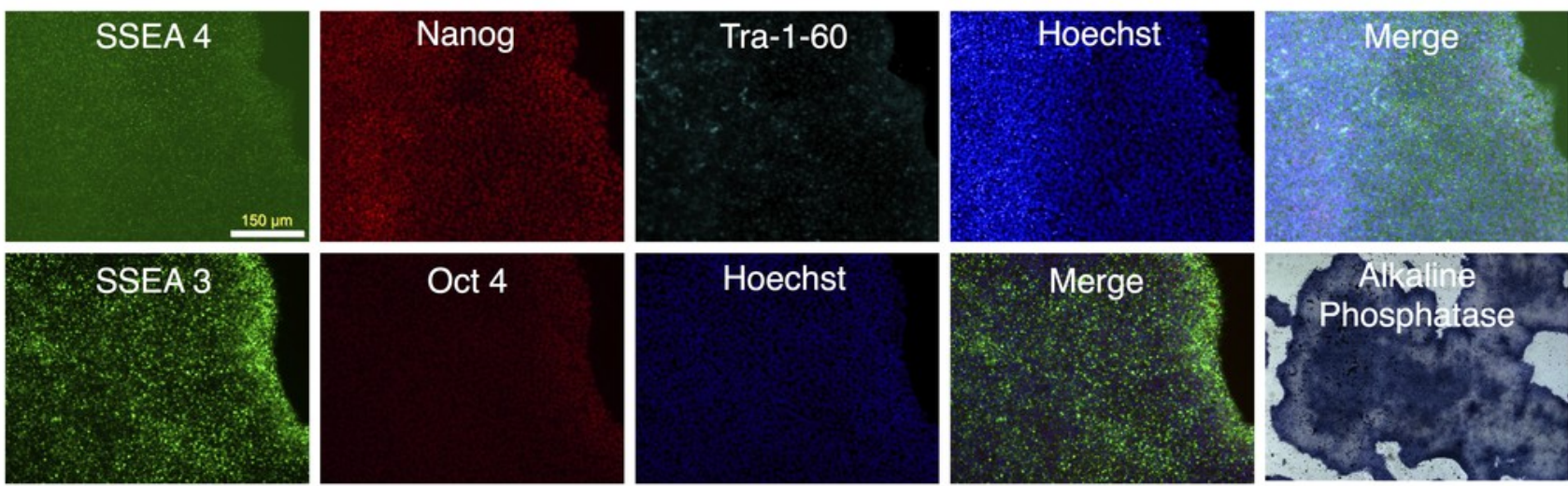

B

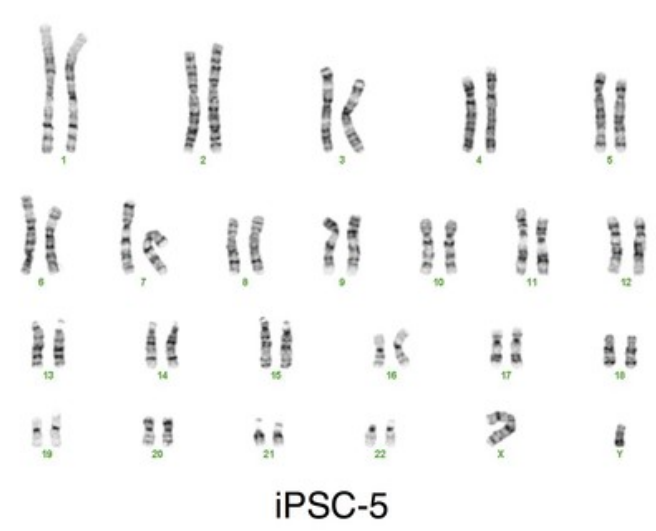

C

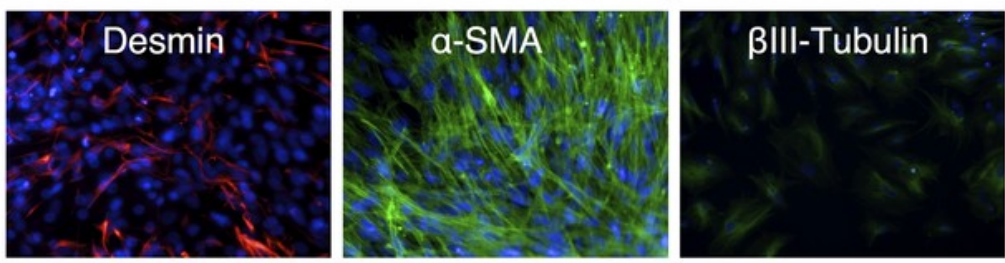




\section{Figure 7}

Reprogramming factor and pluripotency related mRNA expression in putative iPSC clones

A) The $\mathrm{RF}_{\mathrm{T}}$ to $R F_{E}$ ratio, determined by $\mathrm{RT}-\mathrm{qPCR}$ of total $\mathrm{RNA}$ isolated from indicated cell types, is shown for untransduced MRC- 5 fibroblasts, vector-transduced MRC- 5 fibroblasts (MRC-5 5V) and derived iPSC clones. The $\mathrm{RF}_{\mathrm{T}} / \mathrm{RF}_{\mathrm{E}}$ ratios were normalized to that observed in $\mathrm{hES}$ cells. Mean \pm standard deviation of the combined $\mathrm{RF}_{\mathrm{T}} / \mathrm{RF}_{\mathrm{E}}$ ratios of all four $\mathrm{RFs}$ are shown above the bars, except for MRC- $55 \mathrm{~V}$ where the individual $R F_{T} / R_{E}$ ratio, while significantly different from $\mathrm{hES}$, also varied significantly between the RFs. B) Expression of NANOG and DNA methyltransferase 3B (DNMT3B) in hES cells, untransduced MRC-5 and transduced MRC-5 (MRC-5 5V), and derived iPSC clones. The mRNA expression was normalized to $\beta$-actin levels in the samples. Error bar represents one standard deviation. The standard deviation of the ratio of means was calculated as described under Materials and Methods. 

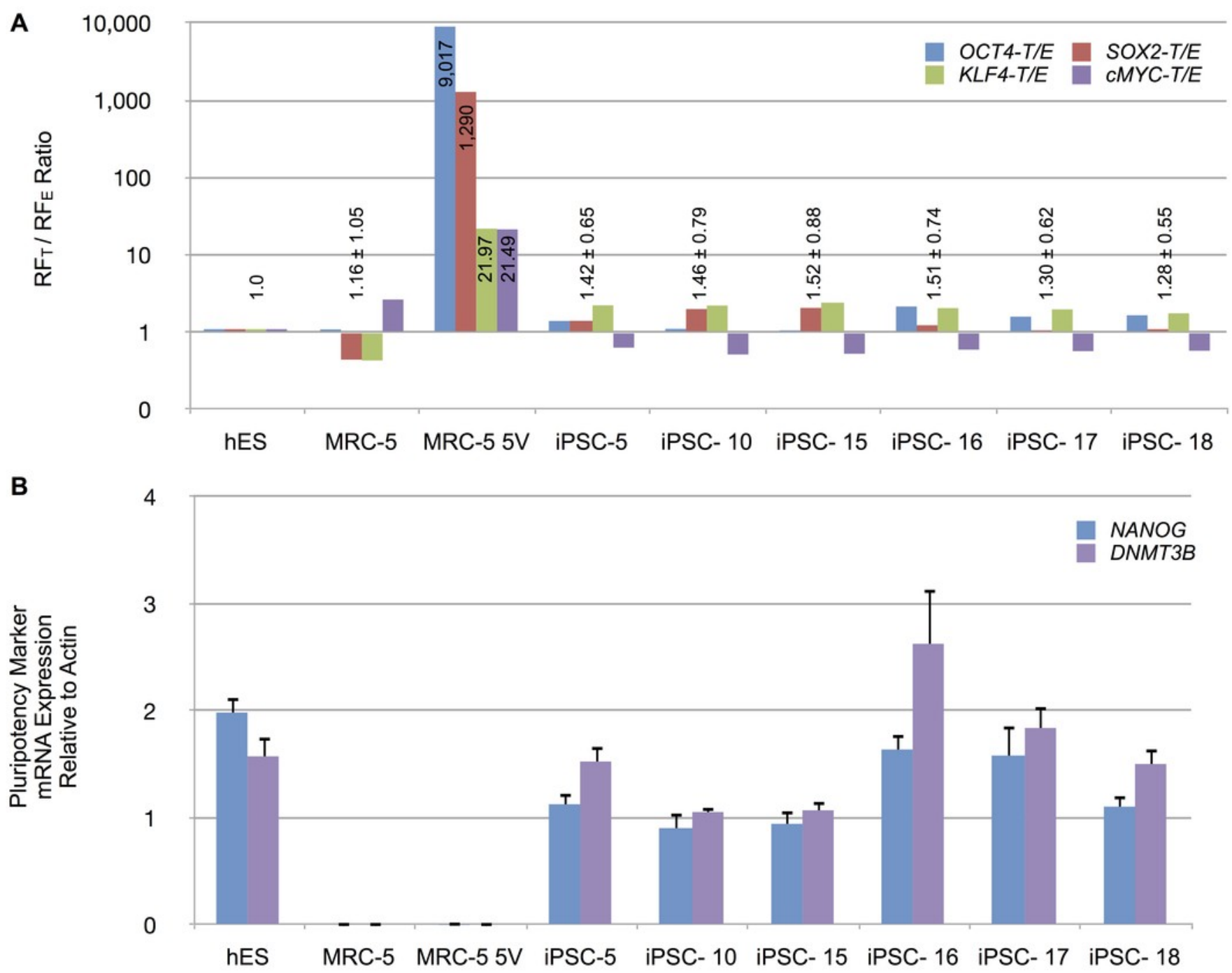


\section{Figure 8}

Methylation analysis of Moloney vector 5' LTR using MSRE-qPCR.

A) Sequence of 5' long terminal repeat (LTR) and untranslated region of Moloney murine leukemia virus. The U3, R and U5 sequences within the LTR are shown and demarcated by vertical lines. Also shown are direct repeats (DR1 and DR2), Tata box, polyadenylation signal (Poly A), negative control region (NCR), binding site for ELP/NR5A1, and primer binding site (PBS). The CpG nucleotides are marked underneath by ' "*' to indicate putative sites of methylation. The methylation sensitive Smal and methylation insensitive Mscl restriction enzyme sites are shown in red and green, respectively. $>>>$ and $<<<$ identify forward and reverse primers used in MSRE-qPCR. B) Genomic DNA from untransduced MRC-5, vector transduced MRC-5 cells (MRC-5 5V), iPSC clones, and MRC-5 control genomic DNA spiked with unmethylated (UPC) or methylated plasmid vector DNA (MPC) was either undigested (Uncut) or digested with Smal or Mscl and then subjected to qPCR for determination of vector 5' LTR or $\beta$-Actin copy numbers. The vector copy numbers per cell was calculated as described in Materials and Methods. Error bars represents one standard deviation. The standard deviation of the ratio of means was calculated as described under Materials and Methods. 
1 AATGAAAGAC CCCACCTGTA GGTTTGgCAA GCTAGCTTAA GTAACGCCAT TTTGCAAGgC

* $\quad$ NCR

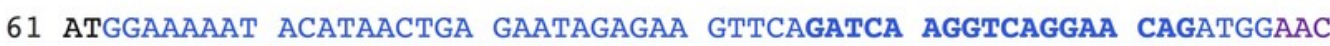
ELP/NR5A1 Binding site

121 AgCTGAATAT GGGCCAAACA GGATATCTGT GGTAAGCAGT TCCTGCCCCG GCTCAGGGCC DR1

181 AAGAACAGAT GGAACAGCTG AATATGGGCC AAACAGGATA TCTGTGGTAA GCAGTTCCTG ‘U3' DR2

241 CCCCGGCTCA GGGCCAAGA CAgATgGtCC CCAGATGCGg TCCAGCCCTC AgCAGTTTCT

301 AgAGAACCAT CAGATGTTTC CAgGGTGCCC CAAgGACCTG AAATGACCCT GTGCCTTATT

361 TGAACTAACC AATCAGTTCG CTTCTCGCTT CTGTTCGCGC GCTTCTGCTC CCCGAGCTCA $\gg$ TATA box *

481 GgtaCCCGTG TATCCAATAA ACCTCTTGC AgtTGCATCC GACTTGTGGT CTCGCTGTTC Poly A

541 CTTGGGAgGg TCTCCTCTGA GTGATTGACT ACCCGTCAgC GGgGGTCTTT CATTTGGGG

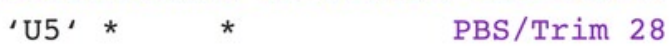

601 CTCGTCCGG ATCGGGAGAC CCCTGCCCAG GGACCACCGA CCCACCACCG GGAGGTAAGC

661 TGGCCAGCAA CTTATCTGTG TCTGTCCGAT TGtCTAGTGT CTATGACTGA TTTTATGCGC MscI

721 CTGCGTCGGT ACTAGTTAGC TAACTAGCTC TGTATCTGGC

$<<<*<*<<<<<<<<<<<<<~$

B

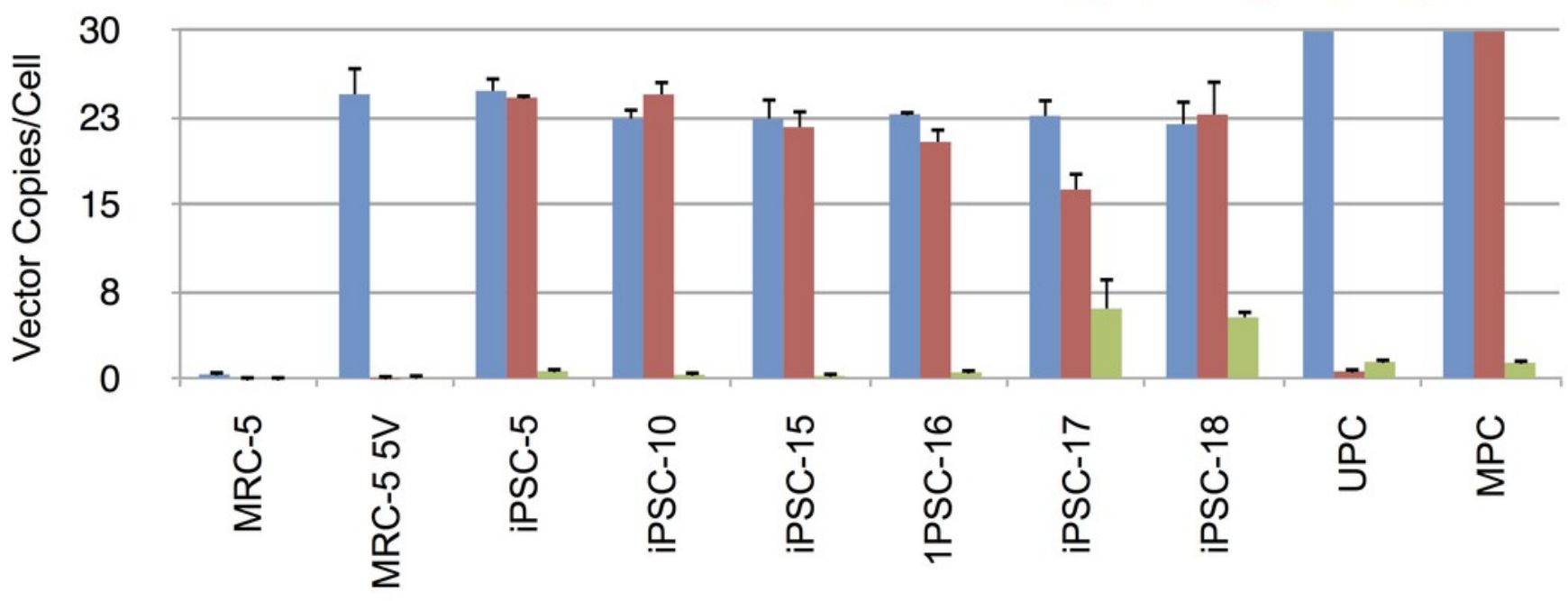




\section{Figure 9}

Embryoid body derivation from an mRFP1-negative iPSC clone.

IPSCs growing in log phase were released with Dispase treatment and allowed to form embryoid bodies in low-attachment flasks as described in Materials and Methods. The flasks were observed periodically (at the indicated intervals) under the microscope and photographed.

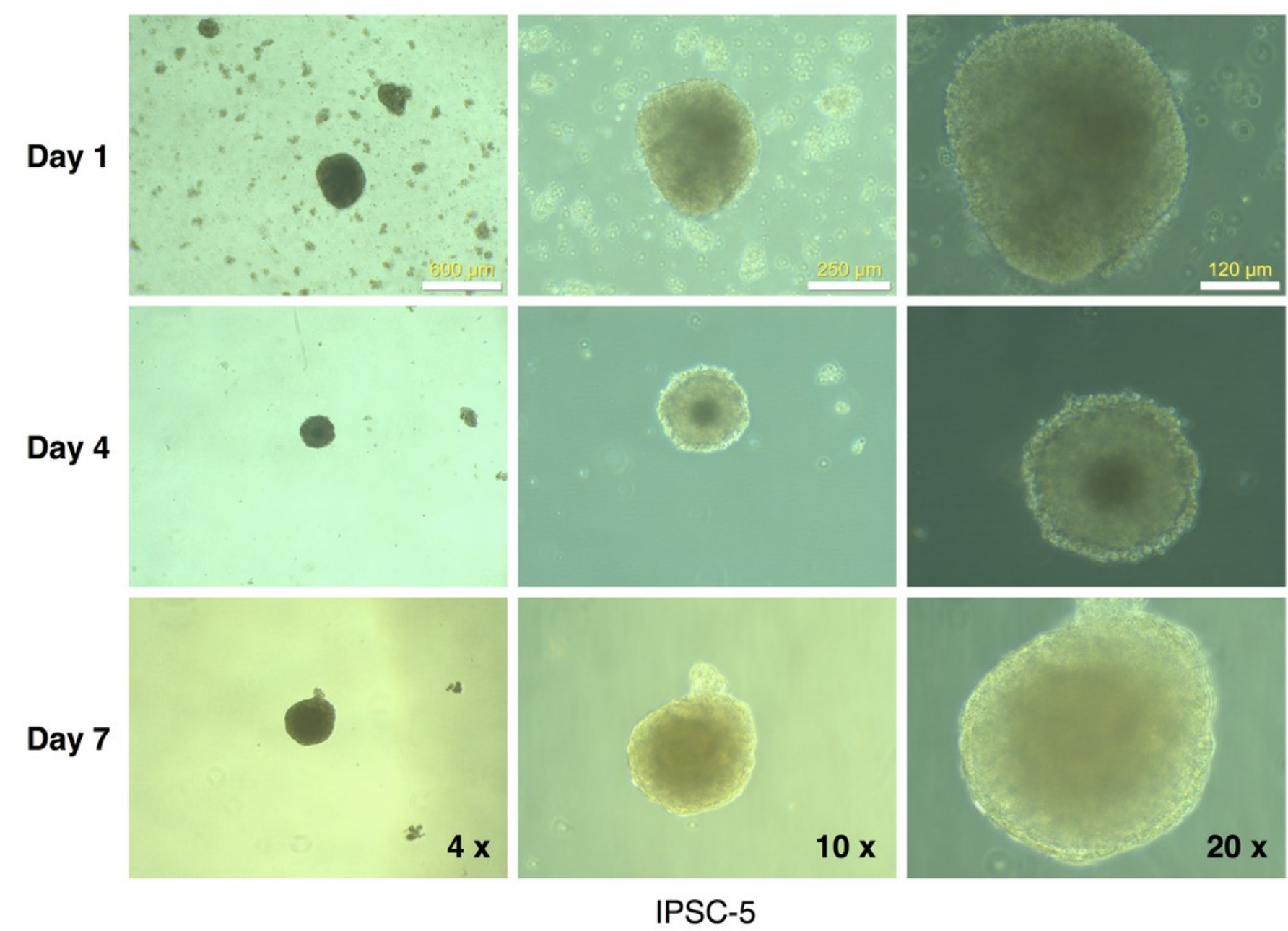




\section{Figure 10}

Putative IPSC colony showing mRFP1-positive and mRPF1-negative cells.

mRFP-negative colonies were picked using a pulled glass Pasteur pipet as described in Materials and Methods and placed in a well with mouse feeder cells. The following day, the well was observed under phase contrast and fluorescence microscopy.
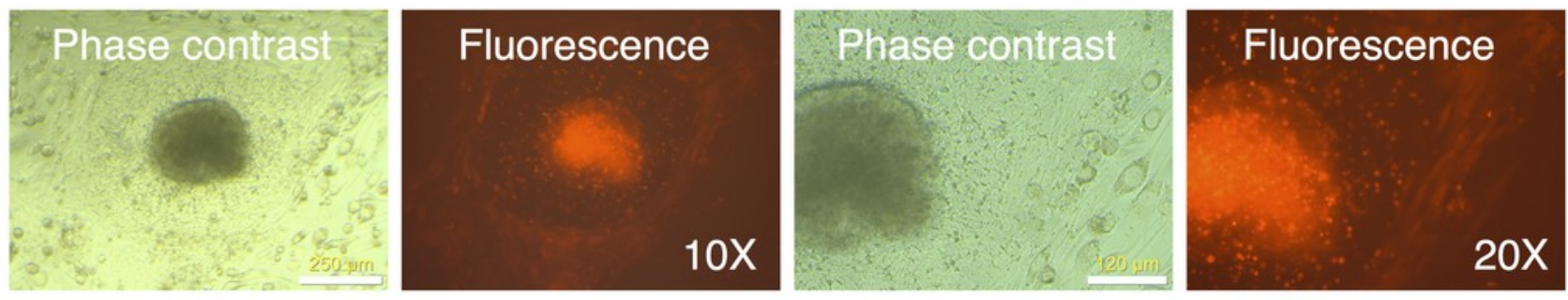


\section{Figure 11}

Live staining of mRFP1-negative colony for Tra-1-60 surface antigen.

A putative iPSC colony with variegated mRFP1 expression was identified on day 7 (dashed white circle). On day 19, the well was stained with Alexa488-labeled antibody to Tra-1-60, a pluripotency marker, and Hoechst 33342 for visualizing nuclei, and then observed by phase contrast and fluorescence microscopy as described in the text.
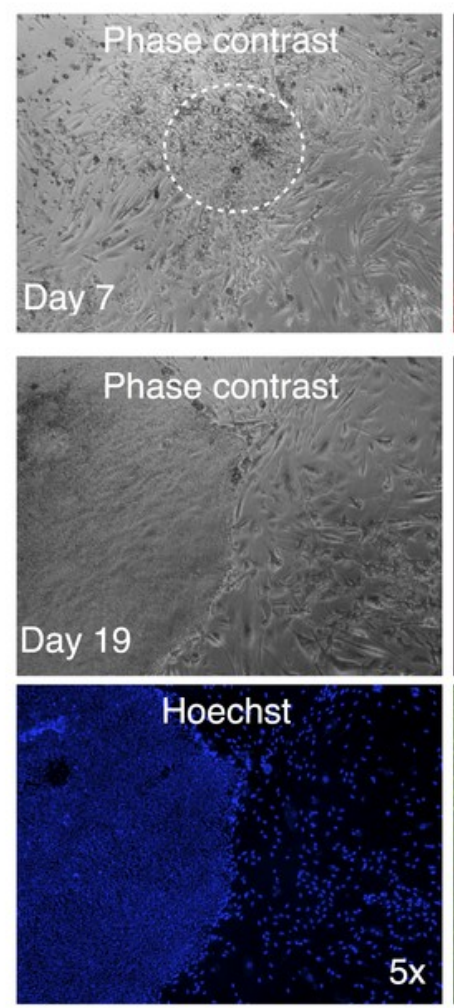
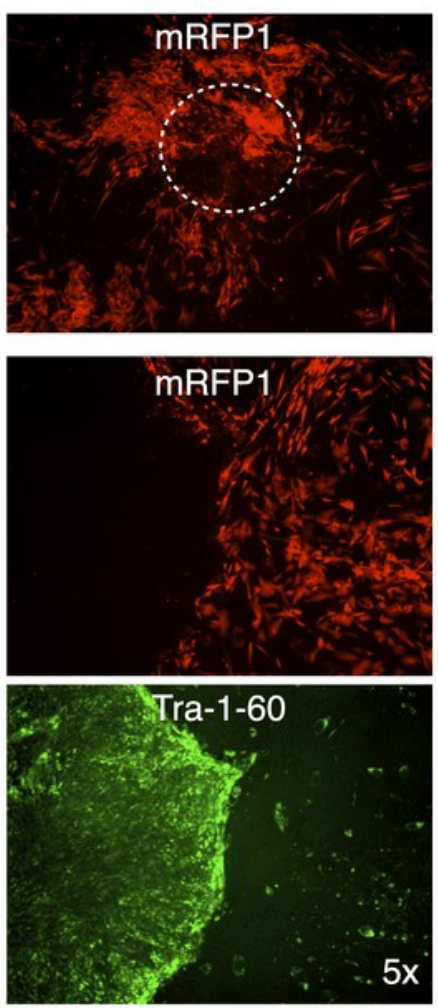
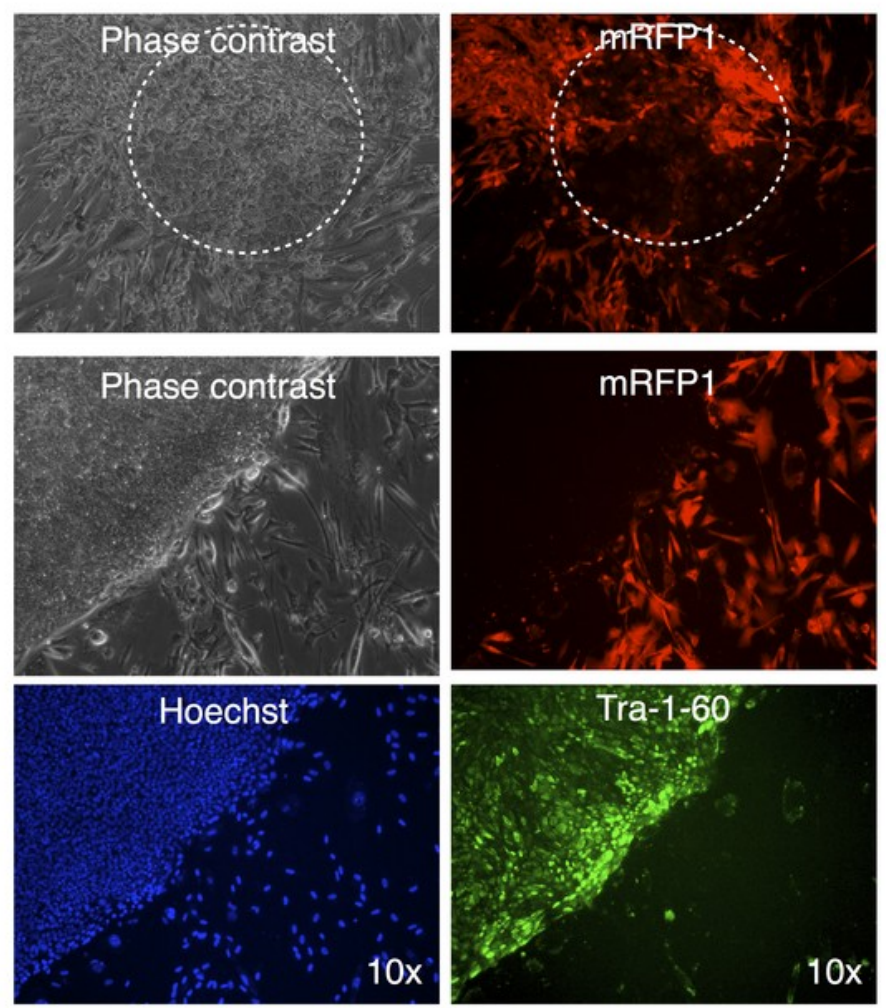


\section{Table 1 (on next page)}

Primers used in qPCR for quantitation of Moloney murine leukemia virus (Mo-MLV) and human $\beta$-actin copy numbers in transduced cells and iPSCs. 
Table 1. Primers used in qPCR for quantitation of Moloney murine leukemia virus (Mo-MLV) and human $\beta$-actin copy numbers in transduced cells and iPSCs.

\section{Laboratory Description (nucleotide position)}

designation

Psi-2 S

Psi-2 AS

Mo-MLV packaging signal, S (751-770)

SK106

SK107

SK160

SK161
Mo: illLV packaging signal, AS (962-981)

Hurpan $\beta$-actin, S (477-497)

Huminan $\beta$-actin, AS (706-726)

Mo-MLV U3 ${ }^{a}, S(8219-8238)$

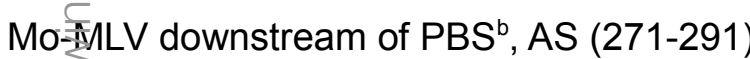

$\begin{array}{lll}\begin{array}{l}\text { Product } \\ \text { size }\end{array} & \text { Sequence }\left(\mathbf{5}^{\prime} \mathbf{-} \mathbf{3}^{\prime}\right) & \begin{array}{l}\text { Parent GenB } \\ \text { Accession No. }\end{array} \\ 231 \mathrm{bp} & \text { CAACCTTTAACGTCGGATGG } & \text { J02255.1 } \\ & \text { GAGGTTCAAGGGGGAGAGAC } & \text { J02255.1 } \\ & \text { CATGTACGTTGCTATCCAGGC } & \text { NM_001101 } \\ & \text { CTCCTTAATGTCACGCACGAT } & \text { NM_001101 } \\ 337 \mathrm{bp} & \text { TCTGCTCCCCGAGCTCAATA } & \text { J02255.1 } \\ & \text { GCTAACTAGTACCGACGCAGG } & \text { J02255.1 }\end{array}$

Product Sequence $\left(5^{\prime}-3^{\prime}\right)$

size
Parent GenBank ssion No.

J02255.1

'U3: Unique 3' region

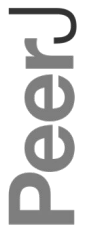




\section{Table 2 (on next page)}

Table 2. Titer determination of Moloney murine leukemia virus vectors encoding RFs or mRFP1 by qPCR. 
Table 2. Titer determination of Moloney murine leukemia virus vectors encoding RFs or mRFP1 by qPCR.

\begin{tabular}{|c|c|c|c|}
\hline Vector & $\begin{array}{l}\text { Vector copy } \\
\text { number }\end{array}$ & $\begin{array}{l}\beta \text {-Actin copy } \\
\text { number }\end{array}$ & Vector titer (IU $1 / \mathrm{ml})$ \\
\hline pMXs-hKLF4 & 6830 & 60,000 & 569,167 \\
\hline pMXs-hOCT3/4 & 2,530 & 48,500 & 260,825 \\
\hline pMXs-hSOX2 & 2,830 & 42,100 & 336,105 \\
\hline pMXs-h-cMYC & 3,780 & 41,100 & 459,854 \\
\hline pMXs-mRFP1 & 2,750 & 30,900 & 444,984 \\
\hline \multicolumn{4}{|c|}{$\begin{array}{l}{ }^{1} \mathrm{IU}=\text { Infectious units } \\
\text { Vector titer }=(\text { Vector copy number } \div(\beta \text {-Actin copy number } \div 2)) \times(\text { number of cells used } \\
\text { for infection }) \times(1,000 \div \text { volume used for infection }) \\
\text { Number of cells used for infection }=250,000\end{array}$} \\
\hline
\end{tabular}




\section{Table 3 (on next page)}

Description of iPSC primers used in RT-qPCR. 
Table 3. Description of iPSC primers used in RT-qPCR

\begin{tabular}{|c|c|c|c|c|c|}
\hline $\begin{array}{l}\text { Laboratory } \\
\text { designation }\end{array}$ & Description (nucleotide position) & $\begin{array}{l}\text { Product } \\
\text { Size }\end{array}$ & Sequence $\left(5^{\prime}-3^{\prime}\right)$ & $\begin{array}{l}\text { Melt } \\
\text { Temp }\end{array}$ & $\begin{array}{c}\text { Parent } \\
\text { GenBank } \\
\text { Accession } \\
\text { No }\end{array}$ \\
\hline AT103 & Humas $\beta$-Actin, S (897-916) & \multirow{2}{*}{84} & CTGTGGCATCCACGAAACTA & 59.7 & \multirow{2}{*}{ NM_001101 } \\
\hline AT104 & Humand $\beta$-Actin, AS (961-980) & & AGCACTGTGTTGGCGTACAG & 60.0 & \\
\hline AT105 & Humañin NANOG, S (347-366) & \multirow{2}{*}{88} & AGATGCCTCACACGGAGACT & 59.9 & \multirow{2}{*}{ NM_024865 } \\
\hline AT106 & Human NANOG, AS (415-434) & & TTGGGACTGGTGGAAGAATC & 59.9 & \\
\hline AT75 & Human DNMT3B, S (1394-1413) & \multirow{2}{*}{203} & ATAAGTCGAAGGTGCGTCGT & 59.8 & \multirow{2}{*}{ NM_006892 } \\
\hline AT76 & Humar DNMT3B AS (1577-1596) & & GGCAACATCTGAAGCCATTT & 60.1 & \\
\hline AT111 & Human OCT4, S (750-771) & \multirow{2}{*}{146} & AAAGCGAACCAGTATCGAGAAC & 59.8 & \multirow{2}{*}{ NM_002701 } \\
\hline AT112 & Humain OCT4, AS (879-898) & & GCCGGTTACAGAACCACACT & 60.0 & \\
\hline AT175 & $\begin{array}{l}\text { Humấ OCT4, S 3'UTR (1243- } \\
\text { 1262) }\end{array}$ & \multirow{2}{*}{55} & AGGAAGGAATTGGGAACACA & 59.4 & \multirow{2}{*}{ NM_002701 } \\
\hline AT176 & Hum OCT4, AS 3'UTR (1279- & & AACCAGTTGCCCCAAACTC & 60.0 & \\
\hline AT65 & Hum $=n$ SOX2, S (1302-1320) & \multirow[b]{2}{*}{151} & CCCAGCAGACTTCACATGT & 57.36 & \multirow[b]{2}{*}{ NM_003106 } \\
\hline AT66 & $\begin{array}{l}\text { Hurnan SOX2, AS 3' UTR (1433- } \\
\text { 1452) }\end{array}$ & & ССТСССАTTTСССТСGTTTT & 57.78 & \\
\hline AT113 & Human SOX2, S (632-651) & \multirow{2}{*}{92} & GATGCACAACTCGGAGATCA & 59.8 & \multirow{2}{*}{ NM_003106 } \\
\hline AT114 & Human SOX2, AS (704-723) & & GCTTAGCCTCGTCGATGAAC & 60.0 & \\
\hline AT115 & Human KLF4, S (2002-2021) & \multirow[b]{2}{*}{110} & CACCTCGCCTTACACATGAA & 59.7 & \multirow[b]{2}{*}{ NM_004235 } \\
\hline AT116 & $\begin{array}{l}\text { Human KFL4, AS 3'UTR (2092- } \\
\text { 2011) }\end{array}$ & & CATCGGGAAGACAGTGTGAA & 59.7 & \\
\hline AT117 & Human KLF4, S(1774-1793) & \multirow{2}{*}{67} & GCCACCCACACTTGTGATTA & 59.4 & \multirow{2}{*}{ NM_004235 } \\
\hline AT118 & Human KLF4, AS (1821-1840) & & GTGCCTTGAGATGGGAACTC & 59.7 & \\
\hline AT177 & Human cMYC, S (1083-1102) & \multirow{2}{*}{94} & CTCCACCTCCAGCTTGTACC & 59.7 & \multirow{2}{*}{ NM_002467 } \\
\hline AT178 & Human cMYC, AS (1157-1176) & & GCTGTCGTTGAGAGGGTAGG & 59.9 & \\
\hline AT179 & Human cMYC, S 5'UTR (119-138) & \multirow[t]{2}{*}{74} & AGGGATCGCGCTGAGTATAA & 59.8 & \multirow{2}{*}{ NM_002467 } \\
\hline AT180 & Human cMYC, AS 5'UTR (173-192) & & TGCCTCTCGCTGGAATTACT & 60.0 & \\
\hline
\end{tabular}




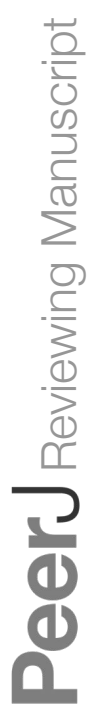

PeerJ reviewing PDF | (v2013:06:561:1:1:NEW 11 Nov 2013) 